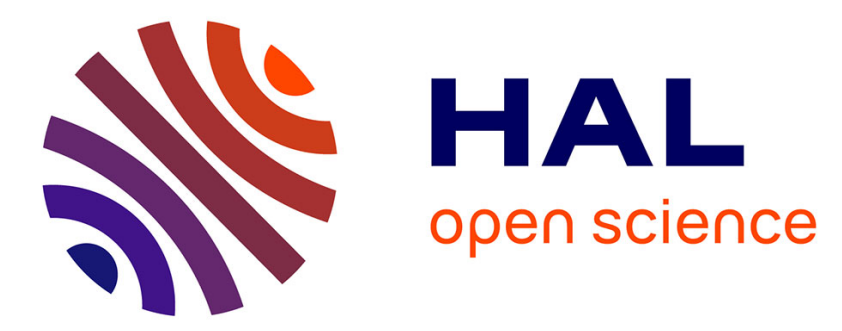

\title{
Engineering the nucleotide coenzyme specificity and sulfhydryl redox sensitivity of two stress-responsive aldehyde dehydrogenase isozymes of Arabidopsis thaliana
}

Naim Stiti, Isaac O. Adewale, Jan Petersen, Dorothea Bartels, Hans-Hubert Kirch

\section{To cite this version:}

Naim Stiti, Isaac O. Adewale, Jan Petersen, Dorothea Bartels, Hans-Hubert Kirch. Engineering the nucleotide coenzyme specificity and sulfhydryl redox sensitivity of two stress-responsive aldehyde dehydrogenase isozymes of Arabidopsis thaliana. Biochemical Journal, 2011, 434 (3), pp.459-471. 10.1042/BJ20101337 . hal-00569402

\section{HAL Id: hal-00569402 https://hal.science/hal-00569402}

Submitted on 25 Feb 2011

HAL is a multi-disciplinary open access archive for the deposit and dissemination of scientific research documents, whether they are published or not. The documents may come from teaching and research institutions in France or abroad, or from public or private research centers.
L'archive ouverte pluridisciplinaire HAL, est destinée au dépôt et à la diffusion de documents scientifiques de niveau recherche, publiés ou non, émanant des établissements d'enseignement et de recherche français ou étrangers, des laboratoires publics ou privés. 


\title{
ENGINEERING THE NUCLEOTIDE COENZYME SPECIFICITY AND SULFHYDRYL REDOX SENSITIVITY OF TWO STRESS-RESPONSIVE ALDEHYDE DEHYDROGENASE ISOZYMES OF ARABIDOPSIS THALIANA
}

\author{
Naim STITI*, Isaac O. ADEWALE ${ }^{\dagger}$, Jan PETERSEN*, Dorothea BARTELS ${ }^{* 1,2}$, Hans-Hubert \\ $\mathrm{KIRCH}^{* 1,2}$ \\ *Institute of Molecular Physiology and Biotechnology of Plants (IMBIO), University of Bonn, \\ Kirschallee 1, 53115 Bonn, Germany; 'Department of Biochemistry, Obafemi Awolowo \\ University, lle-Ife, Nigeria

\begin{abstract}
${ }^{1}$ These authors contributed equally to the work
${ }^{2}$ To whom correspondence should be addressed: e-mail hhkirch@uni-bonn.de, e-mail dbartels@uni-bonn.de.
\end{abstract}

\begin{abstract}
Lipid peroxidation is one of the consequences of environmental stress in plants and leads to the accumulation of highly toxic, reactive aldehydes. One of the processes to detoxify these aldehydes is their oxidation into carboxylic acids catalyzed by $\mathrm{NAD}(\mathrm{P})^{+}$-dependent aldehyde dehydrogenases (ALDHs). We investigated kinetic parameters of two Arabidopsis thaliana family 3 ALDHs, the cytosolic ALDH3H1 and the chloroplastic isoform ALDH3I1. Both enzymes had similar substrate specificity and oxidize saturated aliphatic aldehydes. Catalytic efficiencies improved with the increase of carbon chain length. Both enzymes were also able to oxidize $\alpha, \beta$-unsaturated aldehydes, but not aromatic aldehydes. Activity of ALDH3H1 was NAD -dependent, whereas ALDH3I1 was able to use $\mathrm{NAD}^{+}$and $\mathrm{NADP}^{+}$. An unusual isoleucine residue within the coenzyme-binding cleft was responsible for the ALDH3H1 NAD ${ }^{+}$ dependence. Engineering the coenzyme-binding environment of ALDH3I1 elucidated the influence of surrounding amino acids. Enzyme activities of both ALDHs were redox-sensitive. Inhibition was correlated with oxidation of both catalytic and non-catalytic cysteine residues in addition to homodimer formation. Dimerization and inactivation could be reversed by reducing agents. Mutant analysis showed that cysteines mediating homodimerization are located in the N-terminal region. Modeling of protein structures revealed that the redox-sensitive cysteines are located at the surfaces of the subunits.
\end{abstract}

Short title: Biochemical features of Arabidopsis family 3 aldehyde dehydrogenases

Keywords: Aldehyde dehydrogenase, enzymatic activity, coenzyme specificity, oxidative stress, thiol regulation, site-directed mutagenesis

Abbreviations used: ALDH, aldehyde dehydrogenase; cytMDH, cytosolic malate dehydrogenase; DTNB, 5,5'-dithiobis(2-nitrobenzoic acid); GABA, $\gamma$-aminobutyric acid; GAPDH, glyceraldehyde 3-phosphate dehydrogenase; NADP-MDH, NADP-dependent malate dehydrogenase; Ni-NTA, nickel-nitrilotriacetic acid; P5CDH, $\Delta$-1-pyrroline-5-carboxylate dehydrogenase; ROS, reactive oxygen species; SSADH, succinic semialdehyde dehydrogenase; TNB, 2-nitro-5-mercaptobenzoic acid.

\section{INTRODUCTION}

Plants are subject to diverse environmental constraints which cause an accumulation of reactive oxygen species (ROS) to reach excessive and imbalanced levels. ROS cause disruption of the cellular machinery and homeostasis [1]. The irreversible damage of ROS can be ascribed to two aspects. First, ROS directly interact with a variety of molecules including amino acids, proteins, nucleic acids and membrane lipids, disrupting cell metabolism and integrity [2]. The second component of the ROS-mediated injury is related to lipid peroxidation of polyunsaturated fatty acids which leads to chain breakage. Thus, reactive break- 
down products are generated including saturated and unsaturated hydrocarbons, hydroxyl acids and aldehydes, which in turn propagate ROS-mediated oxidation, thereby exacerbating cellular damage.

Given the high reactivity of ROS and the toxicity of the products generated, plants have evolved a variety of defense strategies. The first line of defense is the regulation of the steady-state level of ROS, which involves the avoidance of ROS formation and the detoxification of reactive products. It includes several enzymatic scavengers such as superoxide dismutase, ascorbate peroxidase, glutathione peroxidase, glutathione-S-transferase, superoxide reductase and hydrogen peroxide oxidoreductase, and a number of molecules like ascorbate, tocopherols, carotenoids and glutathione function as anti-oxidants contributing to protection [1]. The second line of defense is the repair of ROS-mediated damage using molecules like thioredoxins and glutaredoxins.

The harmful effect of surplus amounts of aldehydes is well established [3]. A recent study shows that lipid peroxide-derived aldehydes, especially highly electrophilic $\alpha, \beta$-unsaturated aldehydes are involved in aluminum toxicity in plants and suppression by 2 -alkenal reductase provides an efficient defense mechanism [4]. Despite their toxicity when accumulated in excess, aldehydes are ubiquitous molecules that take part in different physiological processes. For example, induction of hydroperoxide lyase expression leads to enhancement of C6-aldehyde formation after pathogen infection and increases resistance [5]. C6-aldehydes, such as (Z)-3-hexenal, $(E)$-2-hexenal or $n$-hexanal act directly as fungicidal and bactericidal compounds [6,7], that induce the synthesis of the phytoalexin camalexin and subsequent defense responses in Arabidopsis thaliana [8]. Green leafy volatiles, including (Z)-3-hexenal may play a key role in plant-plant signaling and plant-insect interactions [9]. (Z)-3-hexenal activates defense responses during herbivore attack such as transient jasmonic acid biosynthesis and the release of other volatiles, thereby priming plants to respond towards subsequent herbivore attack and simultaneously triggering defense reactions in neighboring plants. Therefore it is crucial to maintain the balance between physiologically essential and deleterious levels. One of the major detoxification processes of excessive aldehydes is their oxidation into the corresponding carboxylic, which is catalyzed by aldehyde dehydrogenases (ALDHs; E.C. 1.2.1.3) using $\mathrm{NAD}^{+}$and $\mathrm{NADP}^{+}$as coenzymes [10].

ALDHs are very diverse as some are substrate specific, whereas others react with a broad array of substrates. In addition, some use either $\mathrm{NAD}^{+}$or $\mathrm{NADP}^{+}$as a coenzyme whereas others can use both. By 2002 over 550 distinct genes encoding ALDHs had been characterized, evolving from archaeal species through green algae and mosses to diverse classes in eukaryotes. Eukaryotic ALDHs are classified into more than 20 families [11]. ALDHs are localized in various subcellular compartments. Crystal structures of ALDHs from different families have been resolved. All have a common architecture and are stabilized by intra-molecular hydrogen bonds; some such as family 1 and 2 enzymes are enzymatically active as homotetramers, whereas others like family 3 ALDHs function as homodimers [12-14]. The Arabidopsis thaliana genome contains 14 genes encoding ALDHs localized in different subcellular compartments [15]. They belong to nine protein families ranging from substrate specific to variable substrate enzymes. Members of $A L D H$ gene families 3,5 and 7 have been reported to respond to environmental stress conditions [15-17].

ALDHs participate in different pathways in plants, but their precise physiological role is often still unclear. Plant ALDHs have gained increasing attention since the maize mitochondrial ALDH2B2 was identified as the $r f 2 a$ gene, which is a nuclear restorer of cytoplasmic male sterility [18, 19]. A mitochondrial family 2 ALDH in rice may be responsible for acetaldehyde detoxification during reaeration after submergence [20]. Nair et al. [21] showed that the reduced epidermal fluorescence 1 (refl) mutant of Arabidopsis is caused by a mutation in the ALDH2C4 gene (At3g24503), which is involved in the biosynthesis of ferulic and sinapic acid. A recent study suggests that $A L D H 2 B 4$ is involved in the pyruvate dehydrogenase bypass pathway in Arabidopsis [22]. Overexpression of ALDH3I1 in A. thaliana improved stress tolerance when plants are exposed to osmotic, oxidative or heavy metal stress [23]. Similarly, ectopic expression of an $A L D H 7$ gene from soybean enhances stress tolerance [24]. ALDH3II and $A L D H 7 B 4$ T-DNA knockout mutant lines exhibit higher sensitivity to dehydration and salt than wildtype plants [25]. The Arabidopsis SSADH1 (ALDH5F1) gene encodes a mitochondrial succinic semialdehyde dehydrogenase, and constitutes a member of the GABA-shunt pathway [26]. T-DNA mutants of SSADH1 are dwarf plants with necrotic lesions and enhanced sensitivity to UV-B irradiation 
and heat stress coupled with an increase in $\mathrm{H}_{2} \mathrm{O}_{2}$ levels, suggesting that this enzyme may decrease ROS intermediates [17]. A mitochondrial $\Delta^{1}$-pyrroline-5-carboxylate dehydrogenase ( $\mathrm{P} 5 \mathrm{CDH}$, ALDH12A1) is probably involved in the prevention of proline toxicity [27]. The biochemical properties of plant ALDHs have been studied only in a few cases [16, 28-31].

Redox regulation of protein thiol groups modulates reactions in biological pathways, including environmental stress responses [32]. We have previously shown that ALDHs contribute to the alleviation of ROS accumulation [25], which could indicate that enzymatic activities are subject to redox regulation. The objective of the present work was to biochemically characterize the Arabidopsis ALDH3H1 and ALDH3I1 enzymes which are localized in different cellular compartments. We identified the catalytically active cysteine residues, and investigated the coenzyme affinities by engineering the coenzyme-binding pockets. Both enzymes undergo thiol oxidation and are susceptible to homodimerization under oxidizing conditions. Their activities are regulated by the reduction of intermolecular disulfide bonds and regeneration of oxidized thiol groups.

\section{EXPERIMENTAL}

\section{Recombinant DNA techniques, DNA sequencing and computational analysis}

Manipulation of nucleic acids was carried out according to Sambrook et al. [33]. DNA sequencing was done by Macrogen Inc., Seoul, Korea. Amino acid sequences were aligned with AlignX program (Invitrogen, Vector NTI-Suite v. 10) and edited with GeneDoc [34]. SWISS-MODEL [35] was used to perform automated homology modeling of ALDH3H1 and ALDH3II based on the available 3D structure of rat ALDH3A1 (acc. no. P11883, PDBe Entry: 1ad3) [14]. The predicted three-dimensional models were visualized using PyMol as a PDB viewer (www.pymol.org). The same software was used to perform in silico quaternary structure analyses of the built models.

\section{Expression and purification of recombinant ALDH3H1 and ALDH3I1}

For ALDH3H1 expression an EcoRI DNA fragment (1410 bp, 470 amino acids, nucleotides 197-1607) was subcloned into the pET28a-expression vector (Novagen, Madison, WI) yielding a fusion protein of 528 amino acids with an N-terminal His-tag. The ALDH3H1 fragment was amplified by PCR from a cDNA clone (accession number AY072122), with the following primers (restriction sites are shown in bold): sense primer, position 183-204, 5'-CTGCGAAGAAGGAATTCGGATC-3'; antisense primer, position 1620-1596, 5'-AGAAGGACTTTGAATTCATCGAAT-3'. As a result of this cloning strategy the C-terminal part of the ALDH3H1 amino acid sequence is 24 aa longer and contains two additional cysteine residues. To avoid the possibility that the two additional cysteine residues affect the analyses, a stop codon was inserted downstream of the 3' EcoRI site by mutagenesis PCR.

For ALDH3I1 expression an EcoRI/XhoI DNA fragment (1470 bp, 490 amino acids, nucleotides 1951665 ) was subcloned into the pET28a-expression vector yielding a fusion protein of 534 amino acids with an N-terminal and C-terminal His-tag. The ALDH3I1 fragment was amplified by PCR from a cDNA clone (accession number AJ306961), with the following primers (restriction sites are shown in bold): sense primer, position 178-200, 5'-CCTTATCGGTTGGAATTCACTTG-3'; antisense primer, position 1681-1659, 5'-CTTTAGAGAACTCGAGGAAAGCC-3'. The recombinant protein thus lacks most of the chloroplastic signal peptide, except for 8 amino acids including the cysteine residue at amino acid position 55 (Supplementary Figure S2). The ALDH3H1 and ALDH3I1 expression constructs were transformed into $E$. coli strain BL21 (DE3).

Purification of soluble recombinant ALDH3H1 and ALDH3I1 proteins was performed by metal ion affinity chromatography on His-tag binding columns (Sigma-Aldrich, St. Louis, MO) under native conditions [16] with the following changes. Bacterial cultures were pre-incubated for $30 \mathrm{~min}$ at $24^{\circ} \mathrm{C}$ and induced by adding IPTG to $0.1 \mathrm{mM}$ for $3 \mathrm{~h}$ at $24^{\circ} \mathrm{C}$. Bacterial cell pellets were resuspended in extraction 
buffer (50 mM HEPES/NaOH pH 7.4, $300 \mathrm{mM} \mathrm{NaCl,} \mathrm{10 \%} \mathrm{(v/v)} \mathrm{glycerol,} \mathrm{0.1 \%} \mathrm{(v/v)} \mathrm{Triton} \mathrm{X-100,} 1.5$ $\mathrm{mM} \beta$-ME (freshly added)) supplemented with $10 \mathrm{mg} / \mathrm{ml}$ lysozyme and $5 \mathrm{mM}$ imidazole. Purified proteins were eluted in $250 \mu \mathrm{l}$ fractions with extraction buffer containing $250 \mathrm{mM}$ imidazole. Eluted peak protein fractions (e.g. fraction 4 for ALDH3H1 and fraction 5 for ALDH3I1, Figure S1) were selected and adjusted to $50 \%(\mathrm{v} / \mathrm{v})$ glycerol, $1 \mathrm{mM}$ PMSF, $0.5 \mathrm{mM} \mathrm{NAD}^{+}$and $6 \mathrm{mM}$ DTT to stabilize enzymes before storage at $-80^{\circ} \mathrm{C}$ for further use. The peak fractions always had a comparable protein yield and activity (Table S2). Protein concentrations were determined with the Bradford protein assay (Bio-Rad, Munich, Germany) using bovine serum albumin (BSA) as standard. Purity of eluted proteins was verified by SDS-PAGE analysis and immunoblotting with anti-ALDH antiserum [25].

\section{Oxidation and reduction of recombinant ALDH3H1 and ALDH3I1}

Purified proteins were oxidized by incubation with $50 \mu \mathrm{M} \mathrm{CuCl}_{2}$ for $1 \mathrm{~h}$ at room temperature. Subsequently, the redox state of the enzymes was assessed by $10 \%$ non-reducing SDS-PAGE. Prior to the oxidation, protein fractions were dialyzed against $50 \mathrm{mM}$ HEPES ( $\mathrm{pH}$ 7.4) using PD-10 desalting columns (GE Healthcare Biosciences, Uppsala, Sweden). To reduce oxidized ALDH3H1 and ALDH3I1, fractions were incubated for $1 \mathrm{~h}$ at room temperature with various concentrations of DTT or GSH (Roth, Karlsruhe, Germany). Following the re-reduction, the redox state of the proteins was confirmed by $10 \%$ non-reducing SDS-PAGE.

\section{Quantification of free sulfhydryl groups}

Purified ALDH3H1 and ALDH3I1 proteins were oxidized by incubation with $50 \mu \mathrm{M} \mathrm{CuCl}_{2}$ for $2 \mathrm{~h}$ at room temperature and samples were collected at different time points. ALDH activities of the collected samples were measured immediately and free thiol groups were simultaneously determined spectrophotometrically based on Ellman's test [36] using DTNB (5,5'-dithiobis(2-nitrobenzoic acid), Sigma-Aldrich). Two microliters of $20 \mathrm{mM}$ DTNB were added to $18 \mu \mathrm{l}$ of each ALDH sample, mixed with $780 \mu \mathrm{l}$ of $0.1 \mathrm{M}$ potassium phosphate buffer $(\mathrm{pH} 7.4)$ and incubated for $20 \mathrm{~min}$ at room temperature to allow color development. Absorbance of released thiophenol anions (TNB-) was determined at $412 \mathrm{~nm}$. Data were plotted as percentage of the remaining free sulfhydryl groups in the oxidized fractions compared to those initially present in the reduced form.

\section{Construction of ALDH mutants}

All mutants were prepared according to the QuikChange Site-Directed Mutagenesis Kit (Stratagene, La Jolla, CA) with mega-primers carrying the desired mutations. Protein expression and purification of the mutated enzymes were performed as described above. All mutants, the corresponding primers and amino acid positions in the recombinant enzymes are listed in Supplementary Table S1. Mutants are numbered according to the amino acid position in the native proteins. Cysteine mutants Cys45Ser, Cys247Ser and Cys253Ser were produced for the enzyme ALDH3H1 and Cys mutants Cys114Ser, Cys142Ser, Cys286Ser, Cys310Ser, Cys316Ser for the enzyme ALDH3I1. Coenzyme affinity studies were performed using Ile200Val and Ile200Gly mutants for ALDH3H1 and a Val263Ile mutant for ALDH3I1.

\section{ALDH3H1 and ALDH3I1 enzyme activity and determination of kinetic constants}

Enzymatic activity assays and determination of apparent $K_{m}$ and $V_{\max }$ values were performed as described [16]. The assay buffer contained $100 \mathrm{mM}$ sodium pyrophosphate at the respective $\mathrm{pH}$-optima for ALDH3H1 and ALDH3I1, $1.5 \mathrm{mM} \mathrm{NAD(P)})^{+}$(Roche, Mannheim, Germany) and various concentrations of propionaldehyde (Merck, Darmstadt, Germany), hexanal, octanal, nonanal, dodecanal, trans-2-hexenal, trans-2-nonenal (Sigma-Aldrich) or 4-hydroxynonenal (Calbiochem, La Jolla, CA). Coenzyme specificitiy was determined using hexanal and trans-2-nonenal as aldehyde substrates at saturating concentrations, and various concentrations of $\mathrm{NAD}(\mathrm{P})^{+}$. Hexanal was used in these experiments because 
of its higher solubility in aqueous solution. All kinetic parameters are reported as means \pm S.E.M. of at least three independent experiments. Enzyme specific activites are expressed as either $\mu \mathrm{mol} \mathrm{NADH} / \mathrm{min}$ per mg of protein or $\mu$ mol NADPH/min per mg of protein. Catalytic efficiency is expressed as $V_{\max } / K_{m(\text { app }}$ $\left[\mu \mathrm{mol} \mathrm{NAD}(\mathrm{P}) \mathrm{H} \times \mathrm{min}^{-1} \times \mathrm{mg}^{-1}\right.$ per $\mu \mathrm{M}$ aldehyde $] \times 10^{3}$.

\section{RESULTS}

\section{Expression and purification of recombinant Arabidopsis ALDH3H1 and ALDH3I1 proteins}

To examine the biochemical features of ALDH enzymes, ALDH3I1 and ALDH3H1 recombinant proteins were purified. Generally, about three times more soluble ALDH3H1 protein was obtained than ALDH3I1 protein from a comparable amount of bacterial culture. Supplementary Table S2 summarizes the overall yield of both recombinant enzymes in typical purification experiments. Supplementary Figure S1 (A \& C) shows typical purification profiles for both proteins. The identity of the eluted proteins was confirmed by immunoblot analysis (Supplementary Figure S1 B \& D). The SDS-PAGE shows the purity of the protein fractions, resulting in major protein bands for ALDH3H1 and ALDH3I1 of approximately 56 and $58 \mathrm{kDa}$ respectively, corresponding to the monomeric subunits. The purified ALDH3II migrated during SDSPAGE as a tight doublet which may be ascribed to the presence of intra-molecular disulfide bonds generated by oxidation of the subunit molecules.

\section{Kinetic properties of Arabidopsis ALDH3H1 and ALDH3l1}

Activities of purified recombinant ALDH proteins were measured across a broad $\mathrm{pH}$ range using $1 \mathrm{mM}$ hexanal and $1.5 \mathrm{mM} \mathrm{NAD}^{+}$as substrates. The pH-optima for ALDH3H1 and ALDH3I1 were 8.0 and 9.0, respectively (Supplementary Figure S1), which were used in all further enzyme assays.

The preferred substrates were determined using saturated aliphatic aldehydes, unsaturated aliphatic aldehydes, and the hydroxylated aldehyde 4-hydroxynonenal with $\mathrm{NAD}^{+}$as coenzyme. Medium to longchain saturated aldehydes (C-6 to C-12) were preferred as substrates, whereas the short-chain aldehyde propanal was a weak substrate, as determined by the catalytic efficiency $V_{\max } / K_{m}$. Dodecanal was the best substrate with catalytic efficiency values of 4831 for ALDH3H1 and 15028 for ALDH3I1 and a $K_{m}$ of 5 $\mu \mathrm{M}$ and $1.3 \mu \mathrm{M}$, respectively (Table 1). Although the $\alpha, \beta$-unsaturated aldehydes trans-2-hexenal, trans-2nonenal and 4-hydroxynonenal were substrates for both enzymes with regard to $K_{m}$ values, catalytic efficiencies for the unsaturated aldehydes were lower than for the saturated aldehydes of the same carbon chain length. The results suggest that saturated aldehydes are preferred over unsaturated aldehydes, irrespective of chain length.

Coenzyme preference was analyzed in the presence of easily soluble substrates like the saturated aldehyde hexanal and the unsaturated aldehyde trans-2-nonenal (Table 2). A comparison of the kinetic constants for $\mathrm{NAD}^{+}$and $\mathrm{NADP}^{+}$shows that $\mathrm{NAD}^{+}$was the preferred coenzyme for both enzymes. ALDH3I1 was also able to use $\mathrm{NADP}^{+}$to oxidize both substrates, whereas ALDH3H1 was strictly NAD ${ }^{+}$ specific. This was confirmed for other aldehydes as substrates (data not shown). Coenzyme preference of ALDH3I1 was substrate dependent. While oxidation of trans-2-nonenal in the presence of $\mathrm{NADP}^{+}$was characterized by $K_{m}$ values comparable to those found for $\mathrm{NAD}^{+}$, the $K_{m}$ value for hexanal was about 26fold higher with NADP ${ }^{+}$than the corresponding value obtained with $\mathrm{NAD}^{+}$as the nucleotide coenzyme (Table 2A).

\section{Coenzyme specificity is modified by single amino acid substitutions}

Alignment of amino acid sequences revealed that ALDH3H1 and ALDH3F1 are exceptions within the family 3 ALDH (Figure 1A). ALDH3H1 and ALDH3F1 contain an isoleucine residue instead of a valine at a central position in the coenzyme-binding site (Figure 1B). This amino acid position is opposite to the negatively charged glutamate which was shown to bond the 2 '-hydroxyl of the adenine ribose of NAD ${ }^{+}$ [37] (Figure 1A \& B). The isoleucine in this location could explain why ALDH3H1 is only able to use 
$\mathrm{NAD}^{+}$as coenzyme, whereas other family 3 ALDHs function with $\mathrm{NADP}^{+}$or $\mathrm{NAD}^{+}$. To examine this hypothesis, the isoleucine in position 200 was substituted by valine or by glycine to yield

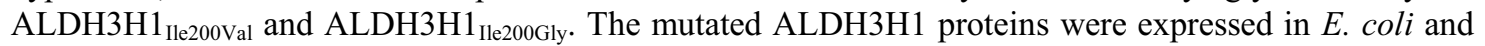
purified to homogeneity. Purification profiles were similar to the wild-type ALDH3H1.

The kinetic properties and coenzyme specificities of the ALDH3H1 mutants were determined using hexanal as substrate at saturating concentrations. Mutating the isoleucine residue to the smaller residues valine or glycine changed the distance between the amino acid at position 200 and Glu-149. This single amino acid exchange altered coenzyme specificity (Table 2). For ALDH3H $1_{\text {Ile220oval }}$ the distance from Val200 across the cleft to Glu-149 is approximately $9.23 \AA$ as determined by structure modeling, which is nearly $1.4 \AA$ larger than the distance in the wild-type ALDH3H1 (7.85 $\AA$ ) (Figure 1D), but similar to ALDH3I1 $(9.22 \AA)$ or the rat ALDH3A1 (9.19 $\AA$ ). The latter two enzymes are able to use NAD ${ }^{+}$as well as $\mathrm{NADP}^{+}$(Figure 1C, E, F \& G). Similarly, the ALDH3H1 $1_{\text {Ile2200val }}$ mutant acquired the ability to use NADP ${ }^{+}$ as coenzyme with a $K_{m \mathrm{NADP}}{ }^{+}$in the same range as the wild-type ALDH3I1. The relative catalytic efficiency of ALDH3H1 $1_{\text {Ile200Val }}$ for $\mathrm{NADP}^{+}$was about $1 \%$ of that for $\mathrm{NAD}^{+}$as deduced from the ratio $\left[V_{\operatorname{maxNAD}}^{+} / K_{m \mathrm{NAD}}{ }^{+}\right] /\left[V_{\operatorname{maxNADP}}+K_{m \mathrm{NADP}}{ }^{+}\right]$. A slight increase was observed in $K_{m \mathrm{NAD}}^{+}$, namely $496 \mu \mathrm{M}$ for the mutated enzyme versus $421 \mu \mathrm{M}$ for the non-mutated ALDH3H1, but no significant negative effect on $V_{\max }$. The ratio $K_{m \mathrm{NAD}^{+}} / K_{m \mathrm{NADP}^{+}}$was 0.21 for the mutant which reflects a higher affinity to $\mathrm{NAD}^{+}$than to NADP $^{+}$. This ratio was still fivefold higher than it was for ALDH3I1, due to the low $K_{m}$ of ALDH3I1 for $\mathrm{NAD}^{+}$which was seven times lower than ALDH3H1 $1_{\text {Ile20oval. }}$

The Ile200Gly mutation exerted the maximal effect on coenzyme binding by ALDH3H1. It caused a lower affinity for $\mathrm{NAD}^{+}$with a $K_{m \mathrm{NAD}}{ }^{+}$nearly eightfold higher than the wild-type ALDH3H1 and about sixfold higher compared to ALDH3H1 $1_{\text {Ile200val }}$ but it had little effect on $V_{\max }$. However, the relative preference for $\left.\mathrm{NAD}^{+}\left(\left[V_{\operatorname{maxNAD}}{ }^{+} / K_{m \mathrm{NAD}}{ }^{+}\right] /\left[V_{\operatorname{maxNADP}}{ }^{+} / K_{m \mathrm{NADP}}\right]\right]\right)$ decreased more than fourfold. Simultaneously, the ability to interact with $\mathrm{NADP}^{+}$as coenzyme increased compared to ALDH3H1 $1_{\text {Ile200Val. }}$. The Ile200Gly substitution led to a $K_{m \mathrm{NADP}}{ }^{+}$lower than the respective Michaelis constant for $\mathrm{NAD}^{+}$and changed the coenzyme preference from $\mathrm{NAD}^{+}$to $\mathrm{NADP}^{+}$. While the wild-type enzyme was strictly dependent on $\mathrm{NAD}^{+}$, the isoleucine-to-valine mutation enabled the enzyme to use $\mathrm{NADP}^{+}$though still preferring $\mathrm{NAD}^{+}$.

The $K_{m}$ values for hexanal were similar for the mutated enzymes, i.e., ALDH3H1 $1_{\text {Ile2200Val }}$ and ALDH3H1 $1_{\text {Ile200Gly }}$ compared to the respective wild-type enzymes (data not shown). This indicates that the interaction with the substrate was not affected by the mutation of the coenzyme-binding site. The increase of the specificity for $\mathrm{NADP}^{+}$coupled with the decrease of the affinity for $\mathrm{NAD}^{+}$parallels the enlargement of the coenzyme binding-site cleft. The differential evolution of the $K_{m}$ values for $\mathrm{NAD}^{+}$and $\mathrm{NADP}^{+}$ suggests that the mutation of Ile-200 to glycine changed the nucleotide specificity of ALDH3H1 from $\mathrm{NAD}^{+}$-dependence to an $\mathrm{NADP}^{+}$-compatible $\mathrm{ALDH}$ with a stronger preference for $\mathrm{NADP}^{+}$in case of ALDH3H1 $1_{\text {Ile200Gly. }}$

To examine whether the presence of the Ile-200 was the only factor influencing the width of the coenzyme binding cleft and consequently determining the ALDH3H1 NAD ${ }^{+}$-dependence, the ALDH3I1 $\mathrm{NAD}(\mathrm{P})^{+}$-binding site was engineered and an isoleucine residue was introduced to replace the orthologous Val-263. This modification did not affect hexanal substrate specificity compared to the saturation kinetics of the wild-type enzyme (data not shown). To compare coenzyme affinities of the mutated enzymes, kinetic parameters of mutated enzyme ALDH3I $1_{\text {Val263Ile }}$ were determined from $\mathrm{NAD}(\mathrm{P})^{+}$saturation curves after full activation with the substrate hexanal (Table 2B). Homology structure modeling suggested that restricting the distance across the coenzyme binding cleft in ALDH3I1 from 9.22 $\AA$ to $7.72 \AA$ as result of the Val263Ile-substitution should decrease the available space to accommodate the 2'-phosphate group of the ribose of NADP ${ }^{+}$. However, the ALDH3I1 $1_{\text {val269lle }}$ variant showed a very good ability to use $\mathrm{NADP}^{+}$as coenzyme. The apparent $K_{m \mathrm{NADP}}{ }^{+}$was reduced more than twofold in comparison to the wild-type enzyme, while the apparent $K_{m \mathrm{NAD}}{ }^{+}$value for ALDH3I1 val263lle was nearly twofold higher than the value for the wild-type enzyme (Table 2B). 


\section{ALDH3H1 and ALDH3I1 proteins form disulfide-linked dimers and multimers under oxidizing conditions}

When ALDH3H1 and ALDH3I1 proteins were treated with $\mathrm{H}_{2} \mathrm{O}_{2}$ or $\mathrm{CuCl}_{2}$ and separated by non-reducing SDS-PAGE, proteins were generated with a molecular weight corresponding to homodimers $(\approx 112 \mathrm{kDa}$ and $\approx 116 \mathrm{kDa}$, respectively) and multimeric bands of higher molecular weight (Figure 2A \& C). This may be attributed to intermolecular disulfide bond formation. To investigate this possibility, oxidized proteins were incubated with increasing concentrations of disulfide bond cleaving reagents DTT or GSH. Figures 2B \& D show that dimers disappeared and conversely monomers were gradually recovered. Efficiency of the reduction of intermolecular disulfide bonds was higher when treated with DTT than with GSH (results not shown).

\section{Enzymatic activities of ALDH3H1 and ALDH3I1 are dependent on their redox states}

To examine whether enzymatic properties of ALDH3H1 and ALDH3I1 proteins are affected by their redox state, enzymatic activities were measured with hexanal as substrate and $\mathrm{NAD}^{+}$as coenzyme under different redox conditions. Oxidation led to a decrease of enzymatic activities to less than 25 to $35 \%$ of the activity of the corresponding reduced forms (Figure 3). Reduction of oxidized ALDH3H1 after incubation with $10 \mathrm{mM}$ DTT for $1 \mathrm{~h}$ resulted in a good recovery of activity to about $83 \%$ of the initial activity, but to only $44 \%$ after reduction with $10 \mathrm{mM}$ GSH (Figure 3A). Oxidation of ALDH3I1 led to a loss of about $70 \%$ of the initial enzymatic activity but could be restored to about $60 \%$ after incubation with $10 \mathrm{mM}$ DTT and to $36 \%$ by treating with reduced glutathione (Figure 3B). This indicates a thiol regulation and rules out unspecific oxidation.

\section{ALDH inactivation is correlated with loss of sulfhydryl groups}

Densitometric analysis of SDS-PAGE patterns indicated the relative amounts of ALDH monomers versus dimers in the different redox conditions. The ratio between dimers and monomers is not well correlated with the observed loss of activity (Supplementary Table S3). Hence, dimers cannot be considered as the only inactive forms of both enzymes and inhibition of activities can also be attributed to a stepwise oxidation of other cysteines (catalytic and non-catalytic cysteines). To examine whether ALDH activity during oxidation is correlated with a loss of other SH groups, enzymatic activity was determined and free thiol groups were quantified simultaneously (see Experimental). During oxidation with $\mathrm{CuCl}_{2}$, the release of TNB revealed a negative linear correlation during the first $65 \mathrm{~min}$, which reflects a constant loss of free sulfhydryl groups (Figure 4A \& B). The fact that ALDH activities of both enzymes were correlated with the number of sulfhydryl groups suggests a thiol-based regulation, which includes sulfhydryl group oxidation as well as homodimerization.

\section{Identification of cysteines critical for enzymatic activities and dimer formation}

To investigate which cysteine residues are involved in dimer formation or contribute to enzyme activities, cysteine residues were individually mutated to serine residues. Enzyme activities and dimer formation of the mutants were analyzed. The native ALDH3H1 subunit contains three cysteines located at amino acid positions 45, 247 and 253 (Supplementary Figure S2). Three single Cys mutants were generated (see Experimental and Supplementary Table S1). ALDH3H1 $1_{\text {Cys247Ser }}$ and ALDH3H1 $1_{\text {Cys253Ser }}$ mutants were as soluble as the wild-type enzyme, whereas the ALDH3H1 $1_{\text {Cys } 45 \text { Ser }}$ mutant was less soluble. Alignment of the amino acid sequences of selected ALDH sequences shows that the residue Cys-253 is conserved (Supplementary Figure S2). Several studies have shown that a cysteine in this position is part of the active centre [38-40].

Similarly, Cys-316 is part of the active centre of ALDH3I1 (Supplementary Figure S2). Mutation of Cys-253 in ALDH3H1 and of Cys-316 in ALDH3I1 abolished enzymatic activity and confirmed that these cysteines belong to the catalytic centre. Mutations of other cysteines led only to partial loss of 
activities. In the case of ALDH3H1 the ALDH3H1 $1_{\text {Cys247Ser }}$ mutant retained about $90 \%$ of the wild-type catalytic activity (Figure 5A).

Cysteine residues of ALDH3I1 at positions 114, 142, 286, 310 and 316 were mutated to serine (Supplementary Table S1). All mutant enzymes were as soluble as the wild-type enzyme. Mutation of Cys-114 to Ser led to a decrease in enzymatic activity of more than $80 \%$, but activities did not change significantly when cysteines in positions 286 or 310 were replaced by serines (Figure 5B). Although residues Cys-45 and Cys-114 in ALDH3H1 and ALDH3I1, respectively, are not conserved between different ALDHs, their mutation to serine caused a decrease of enzyme activity by more than $70 \%$ (Figure $5)$.

The cysteine residues present in ALDH3H1 allow six different possible combinations of intermolecular disulfide bonds between its subunits. However, only the Cys45Ser mutation affected the intermolecular disulfide bond formation which suggests that Cys-45 of ALDH3H1 is the redoxresponsive residue required to form an intermolecular disulfide bond under oxidizing conditions (Figure 6A). Similarly, cysteines of ALDH3I1 involved in the formation of intermolecular disulfide bonds were identified. ALDH3I1 contains nine cysteines. Cysteines at positions 14, 42, 46, and 55 were excluded from the interaction studies, as these cysteines belong to the plastid targeting sequence [16, Supplementary Figure S2] and are not present in the mature protein. Therefore the number of the theoretically possible combinations for disulfide bond formation in the mature ALDH3I1 protein is 15. Only the ALDH3I1 $1_{\mathrm{Cys} 14 \mathrm{Ser}}$ mutant did not form dimers (Figure 6B), indicating that Cys-114 is critical for dimerization.

Cysteine mutant analyses demonstrated that the conserved amino acids, Cys-253 in ALDH3H1 and Cys-316 in ALDH3I1, are critical for the catalytic activity and the N-terminal cysteine residues, Cys-45 in ALDH3H1 and Cys-114 in ALDH311, have a catalytically facilitating role, therefore their oxidation impairs the dehydrogenase activity in addition to their involvement in dimerization.

\section{Oxidation can be reversed and enzyme activity restored}

To confirm the impact of thiol group oxidation and intermolecular disulfide bond formation on ALDH activity, the redox state of the different Cys mutations was determined and enzymatic activities were analyzed. Oxidative treatment resulted in partial inhibition of enzyme activity (Figure 5) and dimerization (Figure 3 and 6). The ALDH3H1 $1_{\text {Cys2475er, }}$ ALDH3I1 $1_{\text {Cys } 142 \text { Ser, ALDH3I1 }}$ Cys286Ser and ALDH3I1 $1_{\text {Cys310Ser }}$ dimers could be gradually reverted to monomers following incubation with sulfhydryl reducing reagents such as GSH or DTT (Figure 7). The release of the monomers from ALDH disulfide bond-linked homodimers was accompanied by a partial recovery of dehydrogenase activity (Figure 5). Densitometric analysis also revealed that the correlation between monomer recovery and the rate of enzyme reactivation is low (Supplementary Table S3). This is further evidence for the involvement of other oxidized thiol groups.

\section{DISCUSSION}

\section{Enzymatic properties}

The focus of the work presented was the biochemical characterization of the Arabidopsis family 3 ALDH enzymes ALDH3H1 and ALDH3I1 which are localized in the cytosol and chloroplasts respectively [16, 25]. Both genes are highly conserved and have probably been maintained by selective pressure indicating that the functions of the gene products are required in cytoplasm and chloroplasts. Analysis of Arabidopsis plants overexpressing ALDH3H1 or ALDH3I1 or carrying null mutants revealed their involvement in stress tolerance $[23,25]$. Here, biochemical properties of purified recombinant enzymes were investigated to associate molecular studies with potential metabolic pathways. All experiments were done with His-tag recombinant enzymes, which allowed purification of sufficient amounts of protein and study of the influence of individual amino acid residues by site-directed mutagenesis. The N-terminal His-tags do not appear to interfere with the active site (Figure 8). 
Kinetic data suggested that both enzymes oxidize medium to long chain aliphatic aldehydes with a preference for long chain aldehydes. Notably, $K_{m}$ values for the unsaturated C9-aldehyde trans-2-nonenal were in the same low range as for the saturated nonanal. Enzymatic data indicated that substrate specificities for the two family 3 Arabidopsis ALDHs were determined by chain length rather than by saturation. This is in contrast to analyses from the enzymatic properties of human and rat ALDH3A1, which show that affinities are generally lower with unsaturated aldehydes than saturated aldehydes [41]. The kinetic parameters of Arabidopsis ALDH3H1 and ALDH3I1 were also different from the two family 2 maize mitochondrial ALDHs, RF2A and RF2B. RF2A is unable to oxidize nonenal, but hexenal is a good substrate with a $K_{m}$ value nearly three times lower than the $K_{m}$ determined for the Arabidopsis enzymes. The other mitochondrial ALDH isoform RF2B is unable to use unsaturated aliphatic aldehydes [29]. Like animal family 3 ALDHs, ALDH3H1 and ALDH3I1 efficiently metabolized 4hydroxynonenal, one of the $\alpha, \beta$-unsaturated aldehydes that accumulates during lipid peroxidation [42]. $K_{m}$ values of both Arabidopsis ALDHs for 4-hydroxynonenal were comparable to those of human and other animal ALDHs [41]. 4-hydroxynonenal is also a very good substrate with a $K_{m}$ in the low micromolar range for the maize mitochondrial RF2A ALDH [29]. In contrast, 4-hydroxynonenal is not a substrate for CpALDH from C. plantagineum, a close ortholog of ALDH3H1 and ALDH3I1 [16], and it is a poor substrate for alfalfa MsALR aldose/aldehyde reductase [43]. The substrate specificities for the ALDH3H1 and ALDH3I1 enzymes were similar except that the chloroplastic enzyme was slightly more efficient with dodecanal as substrate than the cytosolic enzyme, which reacted more efficiently with trans-2-nonenal than the chloroplastic isoform. This may point to substrate specialization related to the two cellular compartments.

\section{Coenzyme specificity}

Coenzyme specificity of ALDH3H1 and ALDH3I1 was correlated with their subcellular localization. The cytosolic ALDH3H1 was unable to utilize $\mathrm{NADP}^{+}$as coenzyme, whereas the chloroplastic ALDH3I1 was able to use either $\mathrm{NAD}^{+}$or $\mathrm{NADP}^{+}$. ALDH3H1 resembles the maize mitochondrial family 2 ALDHs RF2B and RF2A with regard to coenzyme specificity [29]. To our knowledge, this is the first report of a strictly $\mathrm{NAD}^{+}$-specific family 3 ALDH enzyme activity.

Crystal structures of several ALDHs indicate that they bind the coenzyme in a five stranded open $\alpha / \beta$ Rossmann fold [14, 37 and references therein]. Coenzyme specificity in ALDHs is determined by a web of different amino acids, most importantly by a lysine residue, which interacts with the adenine ribose or the 2'-phosphate of $\mathrm{NAD}^{+}$and $\mathrm{NADP}^{+}$, respectively, and a glutamate residue which occupies a central position in the coenzyme binding site and coordinates the adenine ribose 2'- and 3'-hydroxyls of NAD ${ }^{+}$, while repelling the 2'-phosphate of the ribose of adenosine in $\mathrm{NADP}^{+}$[37]. Thus, space in the opposite side of the coenzyme binding cleft is required to keep the $\mathrm{NADP}^{+}$molecule interacting in an active conformation. The $\mathrm{NAD}^{+}$-specific ALDH3H1 has an isoleucine instead of a valine in motif 4 (Figure 1A and Supplementary Figure S2). The isoleucine has a rigid and large hydrocarbon side chain due to an additional methyl group compared to the equivalent valine occupying this position in ALDH3I1. A valine residue is invariant in this position in all family 3 ALDHs except for ALDH3H1 and ALDH3F1 (Figure 1A). Therefore it was tested whether the unusual isoleucine is the reason for the inability to use NADP . $^{+}$ The large $\beta$-branched hydrophobic side chain group oriented towards the coenzyme binding cleft restricts the available space for coenzyme binding. As a consequence it is difficult to accommodate the 2'phosphate of the $\mathrm{NADP}^{+}$molecule while $\mathrm{NAD}^{+}$interaction is not disturbed. This proposed scenario is supported by our observation that after replacing isoleucine by valine the cleft is wider and the distance from the valine to glutamic acid is enlarged to $9.23 \AA$ as determined by modeling (Figure 1 ). This may provide the additional space necessary to accommodate the 2'-phosphate group thus resulting in a mutated enzyme which is able to use $\mathrm{NADP}^{+}$but not affecting $\mathrm{NAD}^{+}$binding (Table $2 \mathrm{~B}$ ).

Inserting glycine in position 200 provided further support that the width of the coenzyme-binding cleft is critical. The removal of the side chain should enlarge the cleft to a width of $11.63 \AA$. This modification impaired the $\mathrm{NAD}^{+}$binding and simultaneously increased the affinity for $\mathrm{NADP}^{+}$(Table 2B). The enlargement of the coenzyme-binding site resulted in a shift in specificity from $\mathrm{NAD}^{+}$to $\mathrm{NADP}^{+}$, 
documented by the relative $K_{m \mathrm{NAD}}+K_{m \mathrm{NADP}}{ }^{+}$ratio. The replacement of isoleucine by glycine provided the space required for accommodation of the 2'-phosphate group of the ribose of $\mathrm{NADP}^{+}$, but the larger space made the cleft too wide to facilitate a tight binding of $\mathrm{NAD}^{+}$. Thus, the large isoleucine side chain is likely to force the adenine ribose of $\mathrm{NAD}^{+}$to a proper distance from the enzyme surface inside the coenzyme binding cleft. Our study elucidates the role of the amino acid residue positioned opposite the glutamic acid in the coenzyme-binding site as determinant of nucleotide coenzyme specificity.

To further examine the influence of isoleucine in coenzyme binding, the valine in ALDH3I1 was replaced by isoleucine. This should create a smaller width across the coenzyme binding cleft and nearly resemble the situation in ALDH3H1. Opposite to our expectations the mutation of ALDH3Il did not alter coenzyme affinities, as binding of $\mathrm{NADP}^{+}$was not weakened. The ALDH3I1 ${ }_{\text {Ile263val }}$ mutant actually exhibited increased affinity for $\mathrm{NADP}^{+}$, which demonstrates that not only the valine but also additional amino acids may influence coenzyme binding. Comparing coenzyme affinities in ALDH3H1 and ALDH3I1 suggests that the coenzyme binding site environment is different in the two enzymes, which may explain the result obtained for the ALDH3I1 $1_{\text {Ile263Val }}$ mutant.

\section{Redox state}

Redox and oligomeric states also determined enzymatic activities of the ALDH proteins. Under oxidizing conditions ALDH3H1 as well as ALDH3I1 were susceptible to thiol oxidation which led to decreased activities. Oxidative inactivation and recovery after reduction allow the conclusion that thiol regulation and not unspecific oxidation takes place. Thiol regulation involves at least one redox-sensitive residue, which is critical for the disulfide bond-mediated dimerization, in addition to other oxidatively modified thiol groups. ALDH3H1 $1_{\text {Cys247Ser }}$ showed enzyme activity and the deactivation rate upon oxidation was very similar to the non-mutated enzyme. However, the Cys253Ser mutation caused a complete inactivation, which supports the crucial role of this cysteine responsible for a nucleophilic attack on the carbonyl carbon of the aldehyde substrate leading to the enzyme-linked thiohemiacetal intermediate during catalysis [38-40]. Mutation of Cys-45, which is not situated in the vicinity of the catalytic site (Figure 8 ), caused a loss of more than $75 \%$ of the initial activity of the wild-type enzyme and abolished intermolecular disulfide bond formation. This suggests that Cys-45 is the redox-responsive residue required to form intermolecular disulfide bonds under oxidizing conditions. This cysteine may act as a sensor and releases active enzyme depending on the redox environment.

ALDH3I1 contains six cysteines (Supplementary Figure S2 and Table S1). As the Cys316Ser mutant was inactive, this proves that Cys-316 is essential for the catalytic activity occupying the same position as Cys-253 in ALDH3H1. The mutation of Cys-114 abolished dimerization under oxidizing conditions and caused a decrease of enzymatic activity, which suggests that Cys-114 is responsible for intermolecular disulfide bridge formation in homodimers. Cysteines mediating redox-dependent dimerization are located in the N-terminal domains of both ALDH isoforms.

Modeling of the three-dimensional structure of Arabidopsis ALDH3H1 and ALDH3I1 was performed using the crystallized ALDH3A1 structure from rat as template [14]. Comparison of the structure of the rat ALDH3A1 and the predicted models of ALDH3H1 and ALDH3I1 revealed that the region corresponding to the domain harboring the cysteines, which form the intermolecular disulfide bridge between two subunits, is located in opposite sides of the hydrogen-linked homodimer (Figure 8). Redoxsensitive cysteines appear to be located in the subunit interface, in a half-buried position. Under reducing conditions the sulfhydryl side chains of Cys- 45 and Cys-114 residues in ALDH3H1 and ALDH3I1, respectively, may spatially not be close enough to establish a disulfide bridge in the hydrogen bond stabilized homodimer interface. Therefore oxidation should trigger conformational changes which alter the surface charges and the hydrophobicity thereby bringing the thiol group into a more exposed and closer position favorable to form intermolecular disulfide bonds with the other subunit. Those changes may also alter enzyme shape into low activity conformation that facilitates additional intermolecular interactions allowing the formation of multimers (Figure 2A \& C).

Densitometric analysis of protein patterns of oxidized fractions showed that the ratio between dimers and monomers does not correlate well with the observed loss of activity (Supplementary Table S3). Thus, 
one can assume that other cysteines were also affected by oxidation. The detection of thiol sulfinate and thiol sulfonate products in MALDI-TOF-MS analysis of monomers in the oxidized fraction of ALDH3H1 supports this assumption (data not shown). It appears that a likely basis for the reversible inactivation of both enzymes under oxidizing conditions is due to the oxidation of their cysteines. Oxidation of ALDHs was always performed by incubation with $50 \mu \mathrm{M} \mathrm{CuCl}_{2}$. Thus it is possible that copper or one of its catalyzed oxidation products reacts with thiols before the generation of disulfides. This might result in an irreversible formation of oxidized thiol products, i.e., sulfenic acid or more highly oxidized forms such as sulfinic and sulfonic acid or oxidation of methionines to methionine sulfoxides, which explains why enzymatic activity could not be completely restored after re-reduction.

Redox sensitivity seems to be a more general feature of dehydrogenase enzymes. Glyceraldehyde 3phosphate dehydrogenase (GAPDH) is susceptible to oxidation. Human GAPDH undergoes disulfide bond formation and loss of thiol groups, which leads to reduction of its enzymatic activity [44]. Similar to oxidized ALDH3H1 and ALDH3I1, GAPDH activity was not fully restored when the oxidized form was treated with reducing agents [45]. Another example is the Arabidopsis cytosolic malate dehydrogenase (cytMDH), which lost activity after oxidation and subsequent homodimer formation; activities could only be partially restored [46]. After nitroglycerin-mediated $S$-nitrosylation a weaker reactivation was reported for mitochondrial ALDH2 [47]. This suggests that reversible thiol oxidation may be an important mechanism for the post-translational control of plant ALDHs.

The inactivation of ALDHs after dimerization under oxidizing conditions was unexpected, since previous in vivo experiments demonstrated that $\mathrm{ALDH} 3 \mathrm{H} 1$ and $\mathrm{ALDH} 3 \mathrm{H1}$ can protect against oxidative stress [25]. Experiments with transgenic plants suggest that both enzymes should be efficient under oxidative stress conditions and able to oxidize toxic lipid peroxidation-derived products. Therefore it seems necessary to maintain aldehyde-detoxifying activities even in an oxidizing environment. This raises the question whether ALDHs interact with another protein partner to avoid the redox modification. It is conceivable that activity could be maintained by involving a physiological reductant such as thioredoxin protecting the amino terminal cysteines [48]. Formation of heterodisulfides between thioredoxin or glutaredoxins and the redox-sensitive cysteines could prevent protein oxidation and loss of activity via homodimerization. This hypothesis seems to be plausible, because it was shown that the redox-sensitive dehydrogenases, cytMDH and GAPDH, are targets of cytosolic thioredoxins [49]. The reduced form of thioredoxin-h1 efficiently reduces and reactivates cytMDH in vitro after oxidation [58]. This assumption is supported by reports that have identified plant ALDHs as potential target proteins for thioredoxin and glutaredoxin [50].

Thioredoxin-dependent activation of redox-sensitive chloroplastic enzymes has been well documented in vascular plants. Chloroplastic NADP-MDH of sorghum is targeted by thioredoxin and it is activated via the reduction of its intramolecular disulfide bridges [51]. Protein-protein interactions involving thioredoxins to modulate dehydrogenase activity in chloroplasts under oxidative stress conditions are an ancient feature. The NADP-MDH from the unicellular green alga Chlamydomonas reinhardtii is also redox-regulated and activated by the thioredoxin-f1 [52]. Thioredoxin regulation has also been reported for chloroplastic GAPDH [53]. We are therefore initiating research to assess the role(s) that thioredoxin and protein:protein interactions may play in the control of ALDH3H1 and ALDH3I1 during oxidative stress.

\section{ACKNOWLEDGEMENTS}

We thank Karolina Podgórska, Frederik Faden and Tobias Diekmann for their help with enzymatic activity studies, and Prof. Dr. Volkmar Gieselmann and Dr. Sebastian Franken (Institute of Biochemistry and Molecular Biology, University of Bonn) for MALDI-TOF analysis. 


\section{FUNDING}

Financial support is gratefully acknowledged to the Deutsche Forschungsgemeinschaft (DFG) Arabidopsis Functional Genomics Network (AFGN) project (BA 712/8-1) and European Molecular Biology Organization (EMBO) (short-term fellowship to Isaac Olusanjo Adewale).

\section{REFERENCES}

1. Apel, K. and Hirt, H. (2004) Reactive oxygen species: metabolism, oxidative stress, and signal transduction. Annu. Rev. Plant Biol. 55, 373-399

2. Wiseman, H. and Halliwell, B. (1996) Damage to DNA by reactive oxygen and nitrogen species: role in inflammatory disease and progression to cancer. Biochem. J. 313, 17-29

3. Mano, J., Miyatake, F., Hiraoka, E. and Tamoi, M. (2009) Evaluation of the toxicity of stress-related aldehydes to photosynthesis in chloroplasts. Planta 230, 639-648

4. Yin, L., Mano, J., Wang, S., Tsuji, W. and Tanaka, K. (2010) The involvement of lipid peroxidederived aldehydes in aluminum toxicity of tobacco roots. Plant Physiol. 152, 1406-1417

5. Shiojiri, K., Kishimoto, K., Ozawa, R., Kugimiya, S., Urashimo, S., Arimura, G., Horiuchi, J., Nishioka, T., Matsui, K. and Takabayashi, J. (2006) Changing green leaf volatile biosynthesis in plants: an approach for improving plant resistance against both herbivores and pathogens. Proc. Natl. Acad. Sci. USA 103, 16672-16676

6. Nakamura, S. and Hatanaka, A. (2002) Green-leaf-derived C6-aroma compounds with potent antibacterial action that act on both Gram-negative and Gram-positive bacteria. J. Agric. Food Chem. 50, 7639-7644

7. Andersen, R. A., Hamilton-Kemp, T. R., Hildebrand, D. F., McCracken Jr., C. T., Collins, R. W. and Fleming, P. D. (1994) Structure-antifungal activity relationships among volatile C6 and C9 aliphatic aldehydes, ketones, and alcohols. J. Agric. Food Chem. 42, 1563-1568

8. Kishimoto, K., Matsui, K., Ozawa, R. and Takabayashi, J., (2008) Direct fungicidal activities of C6aldehydes are important constituents for defense responses in Arabidopsis against Botrytis cinerea. Phytochem. 69, 2127-2132

9. Engelberth, J. Alborn, H. T., Schmelz, E. A. and Tumlinson, J. H. (2004) Airborne signals prime plants against insect herbivore attack. Proc. Natl. Acad. Sci. USA 101, 1781-1785

10. Perozich, J., Nicholas, H. B. Jr., Wang, B. C., Lindahl, R. and Hempel, J. (1999) Relationships within the aldehyde dehydrogenase extended family. Prot. Sci. 8, 137-146

11. Sophos, N. A. and Vasiliou, V. (2003) Aldehyde dehydrogenase gene superfamily: the 2002 update. Chem. Biol. Interact. 143-144, 5-22

12. Moore, S. A., Baker, H. M., Blythe, T. J., Kitson, K. E., Kitson, T. M. and Baker, E. N. (1998) Sheep liver cytosolic ALDH: the structure reveals the basis for retinal specificity. Structure 6, 1541 1551

13. Steinmetz, C. G., Xie, P., Weiner, H. and Hurley T. D. (1997) Structure of mitochondrial aldehyde dehydrogenase: the genetic component of ethanol aversion. Structure 5, 701-711

14. Liu, Z. J., Sun, Y. J., Rose, J. Chung, Y.-J., Hsiao, C. D., Chang, W. R., Kuo, I., Perozich, J., Lindahl, R., Hempel, J. and Wang, B. C. (1997) The first structure of an aldehyde dehydrogenase reveals novel interactions between NAD and the Rossmann fold. Nature Struct. Biol. 4, 317-326

15. Kirch, H.-H., Bartels, D., Wei, Y., Schnable, P. S. and Wood, A. J. (2004) The aldehyde dehydrogenase gene superfamily of Arabidopsis thaliana. Trends Plant Sci. 9, 371-377

16. Kirch, H.-H., Nair, A. and Bartels, D. (2001) Novel ABA- and dehydration-inducible aldehyde dehydrogenase genes isolated from the resurrection plant Craterostigma plantagineum and Arabidopsis thaliana. Plant J. 28, 555-567

17. Bouché, N., Fait, A., Bouchez, D., Møller, S. G. and Fromm, H. (2003) Mitochondrial succinicsemialdehyde dehydrogenase of the gamma-aminobutyrate shunt is required to restrict levels of reactive oxygen intermediates in plants. Proc. Natl. Acad. Sci. USA 100, 6843-6849 
18. Cui, X., Wise, R. P. and Schnable, P. S. (1996) The RF2 nuclear restorer gene of male-sterile, Tcytoplasm maize. Science 272, 1334-1336

19. Liu, F., Cui, X., Horner, H. T., Weiner, H. and Schnable, P.S. (2001) Mitochondrial aldehyde dehydrogenase activity is required for male fertility in maize (Zea mays L.). Plant Cell 13, 1063 1078

20. Tsuji, H., Meguro, N., Suzuki, Y., Tsutsumi, N., Hirai, A. and Nakazono, M. (2003) Induction of mitochondrial aldehyde dehydrogenase by submergence facilitates oxidation of acetaldehyde during reaeration in rice. FEBS Lett. 546, 369-373

21. Nair, R. B., Bastress, K. L., Ruegger, M. O., Denault, J. W. and Chapple, C. (2004) The Arabidopsis thaliana REDUCED EPIDERMAL FLUORESCENCE1 gene encodes an aldehyde dehydrogenase involved in ferulic acid and sinapic acid biosynthesis. Plant Cell 16, 544-554

22. Wei, Y., Lin, M., Oliver, D. J. and Schnable, P. S. (2009) The roles of aldehyde dehydrogenases (ALDHs) in the PDH bypass of Arabidopsis. BMC Biochem. 10 (7)

23. Sunkar, R., Bartels, D. and Kirch, H.-H. (2003) Overexpression of a stress-inducible aldehyde dehydrogenase gene from Arabidopsis thaliana in transgenic plants improves stress tolerance. Plant J. 35, 452-464

24. Rodrigues, S. M., Andrade, M. O., Soares Gomes, A. P., DaMatta, F. M., Baracat-Pereira, M. C. and Fontes, E. P. B. (2006) Arabidopsis and tobacco plants ectopically expressing the soybean antiquitin-like ALDH7 gene display enhanced tolerance to drought, salinity, and oxidative stress. J. Exp. Bot. 57, 1909-1918

25. Kotchoni, S., Kuhns, C., Ditzer, D., Kirch, H.-H. and Bartels, D. (2006) Over-expression of different aldehyde dehydrogenase genes in Arabidopsis thaliana confers tolerance to abiotic stress and protects plants against lipid peroxidation and oxidative stress. Plant Cell Environ. 29, 10331048

26. Busch, K. B. and Fromm, H. (1999) Plant succinic semialdehyde dehydrogenase. Cloning, purification, localization in mitochondria, and regulation by adenine nucleotides. Plant Physiol. 121, 589-597

27. Deuschle, K., Funck, D., Hellmann, H., Däschner, K., Binder, S. and Frommer, W. B. (2001) A nuclear gene encoding mitochondrial Delta-pyrroline-5-carboxylate dehydrogenase and its potential role in protection from proline toxicity. Plant J. 27, 345-356.

28. Šebela, M., Brauner, F., Radová, A., Jacobsen, S., Havliš, J., Galuszka, P. and Peč, P. (2000) Characterization of a homogeneous plant amino aldehyde dehydrogenase. Biochem. Biophys. Act. 1480, 329-341

29. Liu, F. and Schnable, P. S. (2002) Functional specialization of maize mitochondrial aldehyde dehydrogenases. Plant Physiol. 130, 1657-1674

30. Fujiwara, T., Hori, K., Ozaki, K., Yokota, Y., Mitsuya, S., Ichiyanaga, T., Hattori, T. and Takabe, T. (2008) Enzymatic characterization of peroxisomal and cytosolic betaine aldehyde dehydrogenases in barley. Physiol. Plant. 134, 22-30

31. Shin, J.-H., Kim, S.-R. and An, G. (2009) Rice aldehyde dehydrogenase7 is needed for seed maturation and viability. Plant Physiol. 149, 905-915

32. Fedoroff, N. (2006) Redox regulatory mechanisms in cellular stress responses. Ann. Bot. 98, 289300

33. Sambrook, J., Fritsch, E. F. and Maniatis, T. (1989) Molecular Cloning: A Laboratory Manual, 2nd Ed., Cold Spring Harbor Laboratory, Cold Spring Harbor, NY

34. Nicholas, K. B., Nicholas, H. B. Jr. and Deerfield, D. W. II. (1997) GeneDoc: Analysis and Visualization of Genetic Variation. EMBNEW. NEWS 4, 14

35. Bordoli, L., Kiefer, F., Arnold, K., Benkert, P., Battey, J. and Schwede, T. (2009) Protein structure homology modeling using SWISS-MODEL workspace. Nat. Protoc. 4, 1-13

36. Ellman, G. L. (1959) Tissue sulfhydryl groups. Arch. Biochem. Biophys. 82, 70-77

37. Perozich, J., Kuo, I., Wang, B. C., Boesch, J. S., Lindahl, R. and Hempel, J. (2000) Shifting the NAD/NADP preference in class 3 aldehyde dehydrogenase. Eur. J. Biochem. 267, 6197-6203 
38. Farrés, J., Wang, T. T. Y., Cunningham, S. J. and Weiner, H. (1995) Investigation of the active site cysteine residue of rat liver mitochondrial aldehyde dehydrogenase by site-directed mutagenesis. Biochemistry 34, 2592-2598

39. Kitson, T. M., Hill J. P. and Midwinter, G. G. (1991) Identification of a catalytically essential nucleophilic residue in sheep liver cytoplasmic aldehyde dehydrogenase. Biochem. J. 275, 207-210

40. Pietruszko, R., Blatter. E., Abriola, D. P. and Prestwich, G. (1991) Localization of cysteine 302 at the active site of aldehyde dehydrogenase. Adv. Exp. Med. Biol. 284, 19-30

41. Pappa, A., Estey, T., Manzer, R., Brown, D. and Vasiliou, V. (2003) Human aldehyde dehydrogenase 3A1 (ALDH3A1): biochemical characterization and immuno-histochemical localization in the cornea. Biochem. J. 376, 615-623

42. Esterbauer, H., Schaur, R. J. and Zollner, H. (1991) Chemistry and biochemistry of 4hydroxynonenal, malondialdehyde and related aldehydes. Free Radic. Biol. Med. 11, 81-128

43. Oberschall, A., Deák, M., Török, K., Sass, L., Vass, I., Kovács, I., Fehér, A., Dudits, D. and Horváth, G. V. (2000) A novel aldose/aldehyde reductase protects transgenic plants against lipid peroxidation under chemical and drought stresses. Plant J. 24, 437-446

44. Lind, C., Gerdes, R., Schuppe-Koistinen, I. and Cotgreave, I.A. (1998) Studies on the mechanism of oxidative modification of human glyceraldehyde-3-phosphate dehydrogenase by glutathione: catalysis by glutaredoxin. Biochem. Biophys. Res. Commun. 247, 481-486

45. Holtgrefe, S., Gohlke, J., Starmann, J., Druce, S., Klocke, S., Altmann, B., Wojtera, J., Lindermayr, C. and Scheibe, R. (2008) Regulation of plant cytosolic glyceraldehyde 3-phosphate dehydrogenase isoforms by thiol modifications. Physiol. Plant. 133, 211-228

46. Hara, S., Motohashi, K., Arisaka, F., Romano, P. G. N., Hosoya-Matsuda, N., Kikuchi, N., Fusada, N. and Hisabori, T. (2006) Thioredoxin-h1 reduces and reactivates the oxidized cytosolic malate dehydrogenase dimer in higher plants. J. Biol. Chem. 281, 32065-32071

47. Beretta, M., Sottler, A., Schmidt, K., Mayer, B. and Gorren, A.C. (2008) Partially irreversible inactivation of mitochondrial aldehyde dehydrogenase by nitroglycerin. J. Biol. Chem. 283, 3073530744

48. Meyer, Y., Buchanan, B. B., Vignols, F. and Reichheld, J. P. (2009) Thioredoxins and glutaredoxins: unifying elements in redox biology. Annu. Rev. Genet. 43, 335-367

49. Yamazaki, D., Motohashi, K., Kasama, T., Hara, Y. and Hisabori, T. (2004) Target proteins of the cytosolic thioredoxins in Arabidopsis thaliana. Plant Cell Physiol. 45, 18-27

50. Balmer, Y., Vensel, W. H., Tanaka, C. K., Hurkman, W. J., Gelhaye, E., Rouhier, N., Jacquot, J.-P., Manieri, W., Schürmann, P., Droux, M. and Buchanan, B. B. (2004) Thioredoxin links redox to the regulation of fundamental processes of plant mitochondria. Proc. Natl. Acad. Sci. USA 101, 26422647

51. Goyer, A., Decottignies, P., Issakidis-Bourguet, E. and Miginiac-Maslow, M. (2001) Sites of interaction of thioredoxin with sorghum NADP-malate dehydrogenase. FEBS Lett. 505, 405-408

52. Lemaire, S. D., Quesada, A., Merchan, F., Corral, J. M., Igeno, M. I., Keryer, E., IssakidisBourguet, E., Hirasawa, M., Knaff, D. B. and Miginiac-Maslow M. (2005) NADP-malate dehydrogenase from unicellular green alga Chlamydomonas reinhardtii. A first step toward redox regulation? Plant. Physiol. 137, 514-521

53. Fermani, S., Sparla, F., Falini, G., Martelli, P. L., Casadio, R., Pupillo, P., Ripamonti, A. and Trost, P. (2007) Molecular mechanism of thioredoxin regulation in photosynthetic A2B2-glyceraldehyde3-phosphate dehydrogenase. Proc. Natl. Acad. Sci. USA 104, 11109-11114 


\section{TABLES AND FIGURES}

\section{TABLES}

\section{TABLE 1}

\section{Kinetic properties of recombinant Arabidopsis ALDH3H1and ALDH3I1 proteins}

Apparent $K_{m}$ and $V_{\max }$ values were determined for different aldehyde substrates using affinitypurified recombinant enzyme and $\mathrm{NAD}^{+}$as coenzyme. Catalytic efficiency is expressed as $V_{\text {max }} / K_{m}$ (app) $\left[\mu \mathrm{mol} \mathrm{NADH} \times \mathrm{min}^{-1} \times \mathrm{mg}^{-1}\right.$ per $\mu \mathrm{M}$ aldehyde] $\times 10^{3}$ and characterizes aldehydeoxidizing capacity. Data represent mean values \pm S.E.M. from at least three independent experiments.

\begin{tabular}{|c|c|c|c|c|c|c|}
\hline \multirow[b]{2}{*}{ Substrate } & \multicolumn{3}{|c|}{ ALDH3H1 } & \multicolumn{3}{|c|}{ ALDH3I1 } \\
\hline & $K_{m}[\mu \mathrm{M}]$ & $\begin{array}{c}V_{\max }[\mu \mathrm{mol} \mathrm{NADH} \\
\left.\times \mathrm{min}^{-1} \times \mathrm{mg}^{-1}\right]\end{array}$ & $V_{\max } / K_{m}$ & $K_{m}[\mu \mathrm{M}]$ & $\begin{array}{c}V_{\max }[\mu \mathrm{mol} \mathrm{NADH} \\
\left.\times \mathrm{min}^{-1} \times \mathrm{mg}^{-1}\right]\end{array}$ & $V_{\max } / K_{m}$ \\
\hline Propionaldehyde & $510 \pm 59$ & $7.3 \pm 2.7$ & 16 & $53 \pm 1331$ & $10.1 \pm 1.8$ & 1.3 \\
\hline Hexanal & $71 \pm 12$ & $12 \pm 0.6$ & 165 & 29 & $17.3 \pm 2.8$ & 156 \\
\hline Octanal & $29 \pm 4$ & $18 \pm 3.5$ & 17 & $24 \pm 10$ & $16.6 \pm 3.9$ & 701 \\
\hline Nonanal & $8 \pm 2$ & $19.2 \pm 4.1$ & 2318 & $7 \pm 1$ & $20 \pm 4.4$ & 3028 \\
\hline Dodecanal & $5 \pm 1$ & $23.9 \pm 1.4$ & 4831 & $1.3 \pm 0.2$ & $18.8 \pm 1.9$ & 15028 \\
\hline trans-2-Hexenal & $180 \pm 24$ & $2.4 \pm 0.16$ & 13.3 & $151 \pm 18$ & $1.5 \pm 0.1$ & 9.7 \\
\hline trans-2-Nonenal & $3 \pm 0.7$ & $2.9 \pm 0.18$ & 938 & $5.5 \pm 1.9$ & $1.6 \pm 0.5$ & 297 \\
\hline 4-Hydroxynonenal & $40.3 \pm 8$ & $1.4 \pm 0.02$ & 34 & $21 \pm 1.3$ & $0.6 \pm 0.04$ & 28 \\
\hline
\end{tabular}




\section{TABLE 2}

Kinetic parameters of recombinant wild-type (A) and mutated (B) Arabidopsis ALDH3H1 and ALDH3l1 comparing NAD ${ }^{+}$and $\mathrm{NADP}^{+}$as coenzymes

Apparent $K_{m}$ and $V_{\max }$ values for the coenzymes $\mathrm{NAD}^{+}$and $\mathrm{NADP}^{+}$were determined with affinity-purified enzymes using and hexanal and trans-2-nonenal as aldehyde substrates. Catalytic efficiency is expressed as $V_{\max } / K_{m(\text { app })}\left[\mu \mathrm{mol} \mathrm{NAD}(\mathrm{P}) \mathrm{H} \times \mathrm{min}^{-1} \times \mathrm{mg}^{-1}\right.$ per $\mu \mathrm{M}$ aldehyde] $\times 10^{3}$ and characterizes aldehyde-oxidizing capacity. Data represent mean values \pm S.E.M. from at least three independent experiments. (na = no activity detected).

\begin{tabular}{|c|c|c|c|c|c|c|}
\hline & & & & & & \\
\hline (A) & & ALDH3H1 & & & $\overline{A L D H 3 I 1}$ & \\
\hline Coenzyme & $K_{m}[\mu \mathrm{M}]$ & $V_{\max } \underset{\left.\times \mathrm{mg}^{-1}\right]}{[\mu \mathrm{mol}} \times \min ^{-1}$ & $V_{\max } / K_{m}$ & $K_{m}[\mu \mathrm{M}]$ & $\begin{array}{c}V_{\max }\left[\mu \mathrm{mol} \times \min ^{-1}\right. \\
\left.\times \mathrm{mg}^{-1}\right]\end{array}$ & $V_{\max } / K_{m}$ \\
\hline $\mathrm{NAD}^{+}{ }_{\text {Hexanal }}$ & $421 \pm 23.5$ & $18.4 \pm 1.7$ & 43.8 & $71 \pm 5$ & $14.1 \pm 1.3$ & 200 \\
\hline $\mathrm{NADP}^{+}{ }_{\text {Hexanal }}$ & na & na & na & $8 \pm 101$ & $3 \pm 0.2$ & 1.6 \\
\hline $\mathrm{NAD}_{\text {Nonenal }}^{+}$ & $119 \pm 25$ & $2.8 \pm 0.8$ & 23 & $53 \pm 6$ & $1.3 \pm 0.2$ & 24 \\
\hline $\mathrm{NADP}^{+}{ }_{\text {Nonenal }}$ & na & na & na & $87 \pm 10$ & $0.5 \pm 0.1$ & 6 \\
\hline (B) & & $\mathrm{NAD}_{\text {Hexanal }}^{+}$ & & & $\mathrm{NADP}^{+}{ }_{\text {Hexanal }}$ & \\
\hline Mutant & $K_{m}[\mu \mathrm{M}]$ & $\begin{array}{c}V_{\max }[\mu \mathrm{mol} \mathrm{NADH} \\
\left.\times \mathrm{min}^{-1} \times \mathrm{mg}^{-1}\right]\end{array}$ & $V_{\max } / K_{m}$ & $K_{m}[\mu \mathrm{M}]$ & $\begin{array}{l}V_{\max }[\mu \mathrm{mol} \text { NADPH } \\
\left.\quad \times \min ^{-1} \times \mathrm{mg}^{-1}\right]\end{array}$ & $V_{\max } / K_{m}$ \\
\hline ALDH3H1 $1_{\text {Ile200Val }}$ & $496 \pm 4$ & $19.8 \pm 1.8$ & 40 & $2300 \pm 76$ & $1.1 \pm 0.1$ & 0.5 \\
\hline ALDH3H $1_{\text {|le200Gly }}$ & $3218 \pm 54$ & $17.4 \pm 1.8$ & 5.4 & $1817 \pm 17$ & $0.6 \pm 0.1$ & 0.3 \\
\hline ALDH3|1 $1_{\text {Val263Ile }}$ & $126 \pm 2$ & $12 \pm 0.2$ & 95.2 & $783 \pm 61$ & $0.66 \pm 0.06$ & 0.8 \\
\hline
\end{tabular}




\section{FIGURE LEGENDS}

\section{Figure 1 The coenzyme-binding site among family 3 ALDHs}

(A) Alignment of amino acid sequences of parts of the coenzyme-binding site among family 3 ALDHs. UniProt accession numbers are listed in brackets. Bovine: ALDH3B1 (Q1JPAO); Human: ALDH3B1 (P43353), ALDH3B2 (P48448), ALDH3A2 (P51648), ALDH3A1 (P30838); Mouse: ALDH3B1 (Q80VQ0), ALDH3A1 (P47739), ALDH3A2 (P47740); Rat: ALDH3B1 (Q5XI42), ALDH3A2 (P30839), ALDH3A1 (P11883); Pongo abelii: ALDH3A2 (Q5RF60); Macaca fascicularis: ALDH3A2 (Q60HH8); Dog: ALDH3A1 (A3RF36); Craterostigma plantagineum: Cp-ALDH (Q8VXQ2); Arabidopsis thaliana: ALDH3H1 (Q70DU8), ALDH3I1 (Q8W033), ALDH3F1 (Q70E96). The conserved glutamate and valine residues are indicated in green and the isoleucine in red. The amino acid sequences shown in blue in (A) correspond to the coenzyme binding site regions modelled in $B$ to $G$. The positions of the amino acids in the native proteins are indicated by numbers on the left and right hand side for each sequence. (B) The positions of amino acids are shown inside the coenzyme binding cleft of ALDH3A1 and ALDH3H1. Location of $\mathrm{NAD}^{+}$and $\mathrm{NADP}^{+}$adenine ribose moieties and amino acid residues in the coenzyme binding site of the previously solved structure of ALDH3A1 from Rattus norvegicus [14] and the predicted Arabidopsis thaliana ALDH3H1 and ALDH3I1 (C to G). The coenzyme binding cleft is magnified from the ribbon diagram of the crystal structure of the ALDH3A1 monomer (panels $\mathrm{C} \& \mathrm{~F}$ ) and the models of ALDH3H1 (panel D) and ALDH3I1 monomers (panels $E$ \& $G$ ). The binary complex ALDH3H1:NADP ${ }^{+}$is not presented, because $\mathrm{ALDH} 3 \mathrm{H} 1$ is an $\mathrm{NAD}^{+}$-dependent dehydrogenase. Amino acid residues discussed to be important for the coenzyme binding (see results) are highlighted either in green for conserved residues or in red for the unusual residue in this position, i.e., isoleucine. Coenzymes NAD (panels C, D \& E) and NADP ${ }^{+}$(panels F \& G) are shown in stick representation and atoms are depicted as follows: oxygen, red; carbon, cyan; phosphorous, orange; nitrogen, blue and hydrogen atoms are hidden. Distances between residues across the coenzyme-binding cleft are indicated in blue. For ALDH3H1 and ALDH3/1, these are estimations based on the homology structure modeling. The predicted structures of ALDH3H1 and ALDH3I1 were generated by the web-based server SWISS-MODEL [35], and rendered using PyMol (www.pymol.org; DeLano Scientific, San Carlos, CA).

\section{Figure 2 Oxidation and reduction of ALDH3H1 and ALDH3I1 proteins}

Recombinant ALDHs were purified as enzymatically active homodimers. Homodimers and multimers were generated by incubating the enzymes $(5 \mu \mathrm{g}$ ALDH3H1 or $10 \mu \mathrm{g}$ ALDH3I1) for $90 \mathrm{~min}$ at room temperature in the presence of $50 \mu \mathrm{M} \mathrm{CuCl}_{2}$ or $1 \mathrm{mM} \mathrm{H}_{2} \mathrm{O}_{2}$. ALDH3H1 (A) and ALDH3I1 (C) proteins were separated by non-reducing 10\% SDS-PAGE. Oxidized ALDH3H1 (B) or ALDH3I1 (D) were incubated with increasing concentrations of DTT for $1 \mathrm{~h}$ at room temperature. Multimeric forms of ALDH3H1 and ALDH3I1 were separated by non-reducing $10 \%$ SDS-PAGE and proteins were detected using PageBlue ${ }^{\mathrm{TM}}$ protein staining solution (Fermentas).

\section{Figure 3 Enzymatic activities depend on the redox states of the ALDH proteins}

ALDH activities of reduced ALDH3H1 (A) and ALDH3I1 (B) (R), after 90 min incubation with 50 $\mu \mathrm{M} \mathrm{CuCl}_{2}(\mathrm{O})$ and after re-reduction by incubation for $1 \mathrm{~h}$ with $10 \mathrm{mM}$ DTT (RrD) or $10 \mathrm{mM}$ reduced glutathione ( $\operatorname{RrG}$, squared bars). The redox states of all tested fractions were analyzed in parallel by non-reducing $10 \%$ SDS-PAGE. All values represent the means \pm S.E.M. of three independent experiments. Asterisks denote statistically significant differences $(P<0.01$, Student's $t$-test). 
Figure 4 ALDH inactivation during oxidation is correlated with loss of sulfhydryl groups

ALDH proteins were treated with $50 \mu \mathrm{M} \mathrm{CuCl}_{2}$ for up to $120 \mathrm{~min}$. Enzyme activities (solid lines) were determined and relative amounts of sulfhydryl groups were measured using Ellman's reagent (DTNB) (dashed lines): ALDH3H1 (A) and ALDH3I1 (B).

Figure 5 Activities of ALDH3H1, ALDH3I1 and their Cys-mutant proteins after oxidation and subsequent re-reduction

Enzyme activities were determined of the purified wild-type ALDH3H1 (A) and ALDH3I1 (B) and the corresponding Cys mutants (A \& B) in different redox states. The bars represent the activities of the following samples: freshly purified proteins $(R)$, proteins oxidized with $50 \mu \mathrm{M}$ $\mathrm{CuCl}_{2}(\mathrm{O})$, proteins oxidized and subsequently reduced by incubation with $10 \mathrm{mM}$ DTT $(\mathrm{RrD})$ or reduced glutathione $(\operatorname{RrG})$. All values represent the means \pm S.E.M. of at least three independent experiments. Asterisks denote statistically significant differences $(P<0.01$, Student's $t$-test). The mutated enzymes ALDH3H1 $1_{\text {cys } 253 \text { Ser }}$ and ALDH $311_{\text {cys } 316 s e r}$ are not shown, because these Cys residues are part of the active centre and the corresponding mutants were inactive.

Figure 6 Redox sensitivities of ALDH3H1 and ALDH311 Cys mutant proteins

Freshly purified ALDH3H1 $(5 \mu \mathrm{g}, \mathrm{A})$ and ALDH3I1 (10 $\mu \mathrm{g}, \mathrm{B})$ Cys mutant proteins were obtained in the reduced form and were subsequently oxidized by incubation with $50 \mu \mathrm{M} \mathrm{CuCl}_{2}$ or $1 \mathrm{mM} \mathrm{H} \mathrm{O}_{2}$ at room temperature for $90 \mathrm{~min}$. Then the redox state of each protein was analyzed by $10 \%$ non-reducing SDS-PAGE. Proteins were visualized using PageBlue ${ }^{\circledR}$ protein staining solution (Fermentas).

Figure 7 Regeneration of monomers from ALDH3H1 and ALDH3I1 Cys-mutants after treatment with different concentrations of DTT

Freshly purified proteins were oxidized by incubation with $\mathrm{CuCl}_{2}$ and then treated with different concentrations of DTT for $1 \mathrm{~h}$ to re-reduce the proteins. The protein samples $(5 \mu \mathrm{g}$ for ALDH3H1 (A) and $10 \mu \mathrm{g}$ for ALDH3I1 (B)) were separated by $10 \%$ non-reducing SDS-PAGE and stained with PageBlue ${ }^{\circledR}$ protein staining solution (Fermentas). Monomers and dimers are shown.

Figure 8 Ribbon and stick diagrams of the predicted structures of Arabidopsis thaliana ALDH3H1 and ALDH3I1 monomeric subunits

Molecules are colored in gray. Green asterisks in the ribbon diagrams denote the central helices of the coenzyme-binding Rossmann-fold domain. Catalytic cysteine residues are depicted in yellow, redox-sensitive cysteines in red, other cysteines in cyan. The insets of the stick diagrams show the location of the redox sensitive cysteines in a half-buried position of the subunits interfaces of ALDH3H1 (A) and ALDH3I1 (B). The predicted structures of ALDH3H1 and ALDH3I1 were built using the web-based modeling server SWISS-MODEL [35] and the solved crystal structure of the Rattus norvegicus ALDH3A1 as template [14]. Obtained structures were rendered using PyMol (www.pymol.org; DeLano Scientific, San Carlos, CA). Regions highlighted in orange in the ribbon diagrams indicate helix $\alpha \mathrm{D}$ and sheets $\beta 12$ as well as $\beta 13$ involved in hydrogen bond-mediated homodimerization in the functional native homologous ALDH3A1 protein [14]. The position of the hexa-His-tag located in the N-terminus is not indicated but represented in the generated models $(*)$. 


\section{Figure 1}

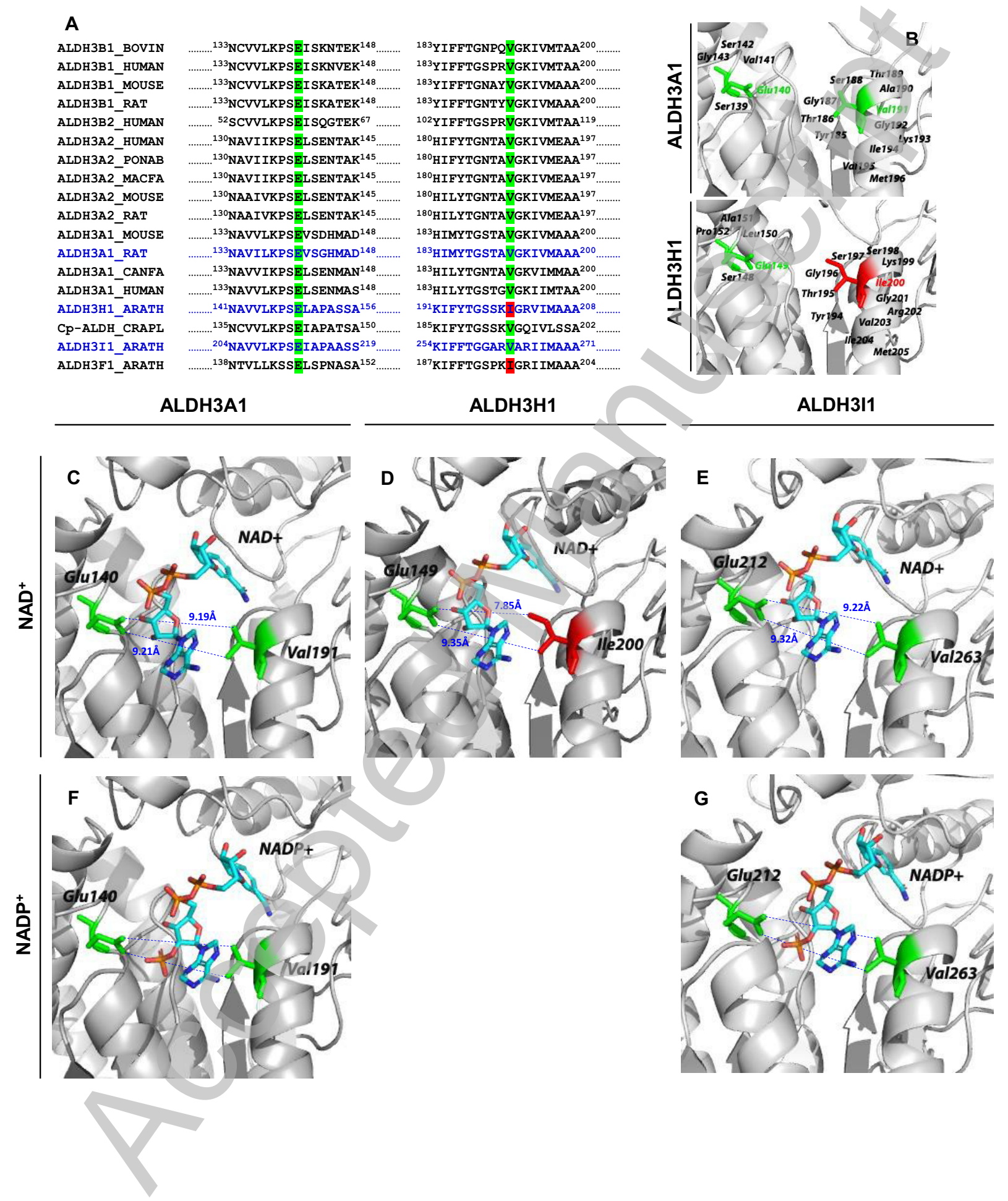

Licenced copy. Copying is not permitted, except with prior permission and as allowed by law. (C) 2010 The Authors Journal compilation (c) 2010 Portland Press Limited 


\section{B Biochemical Journal Immediate Publication. Published on 20 Dec 2010 as manuscript BJ20101337}

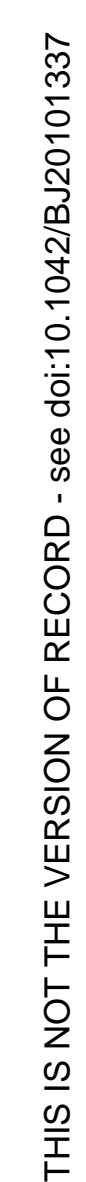

\section{Figure 2}

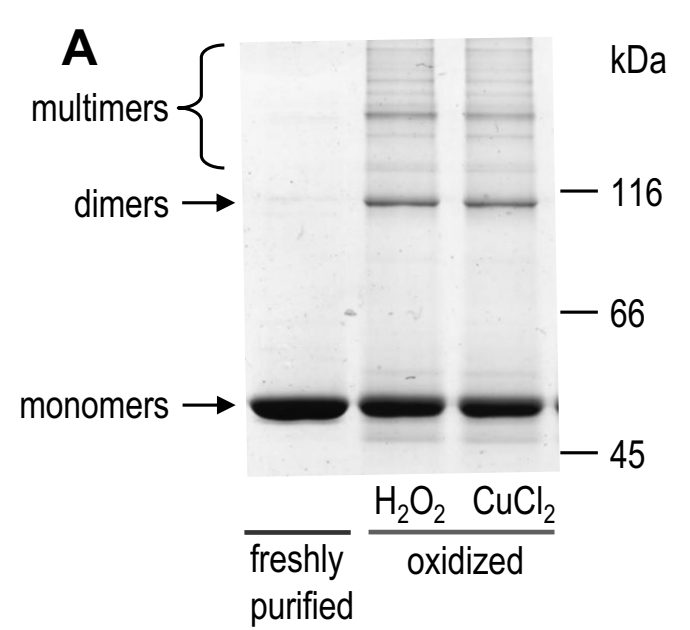

\section{B}

monomers $\rightarrow$

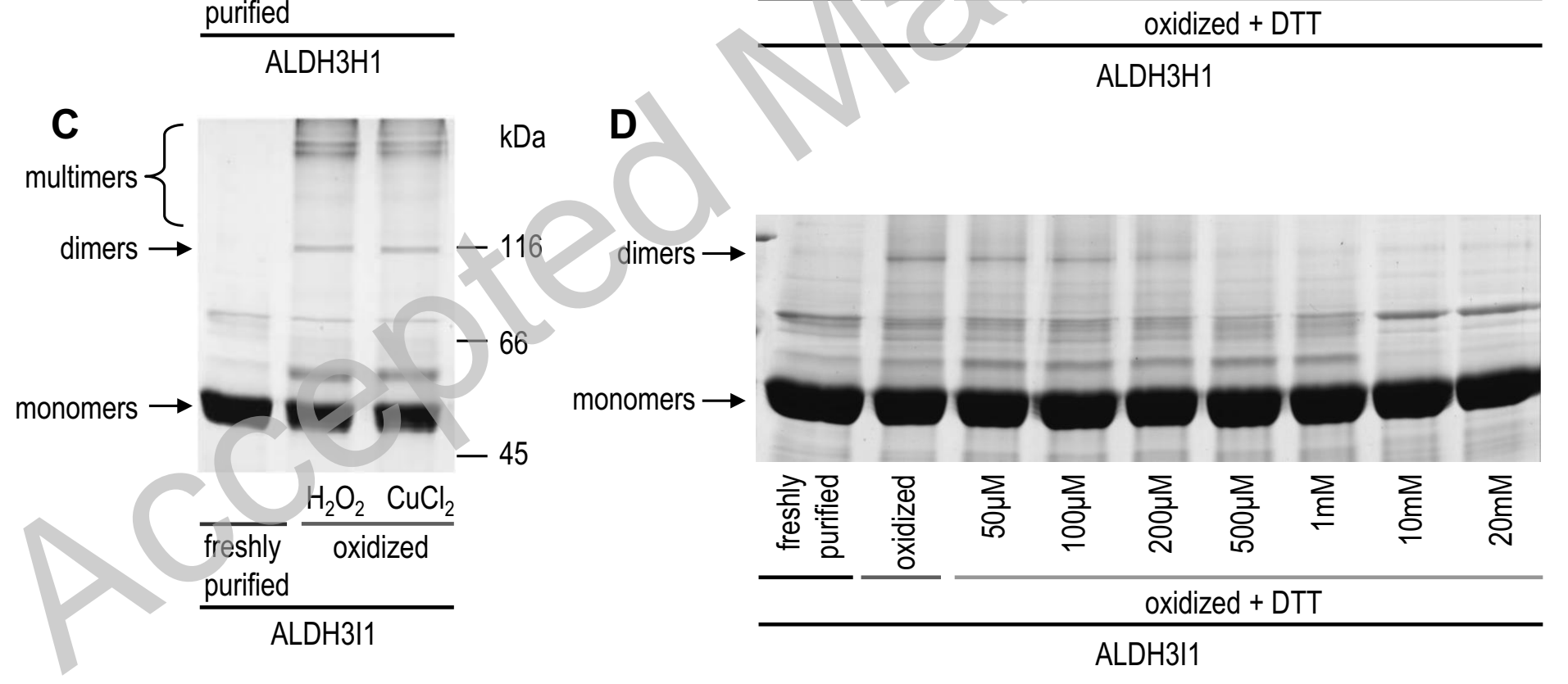

20 


\section{Figure 3}

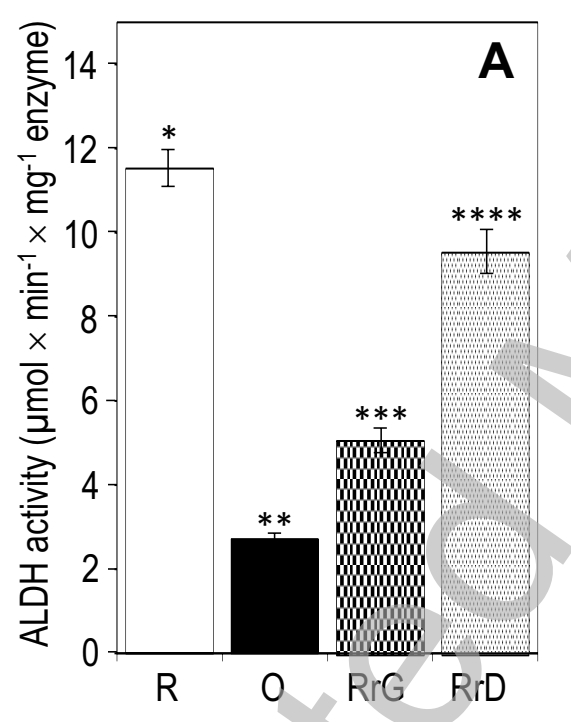

ALDH3H1

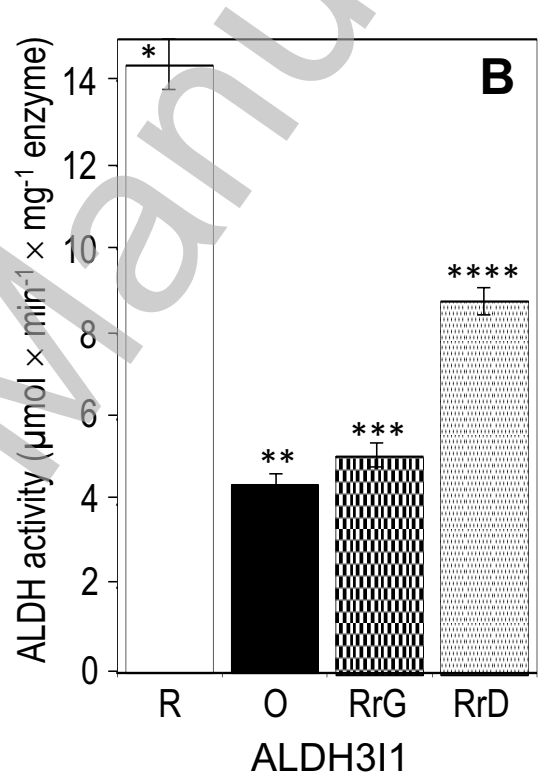


Figure 4

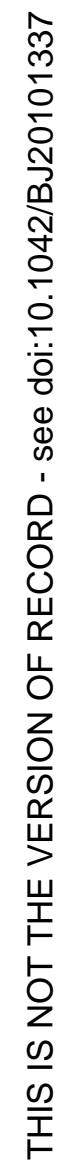
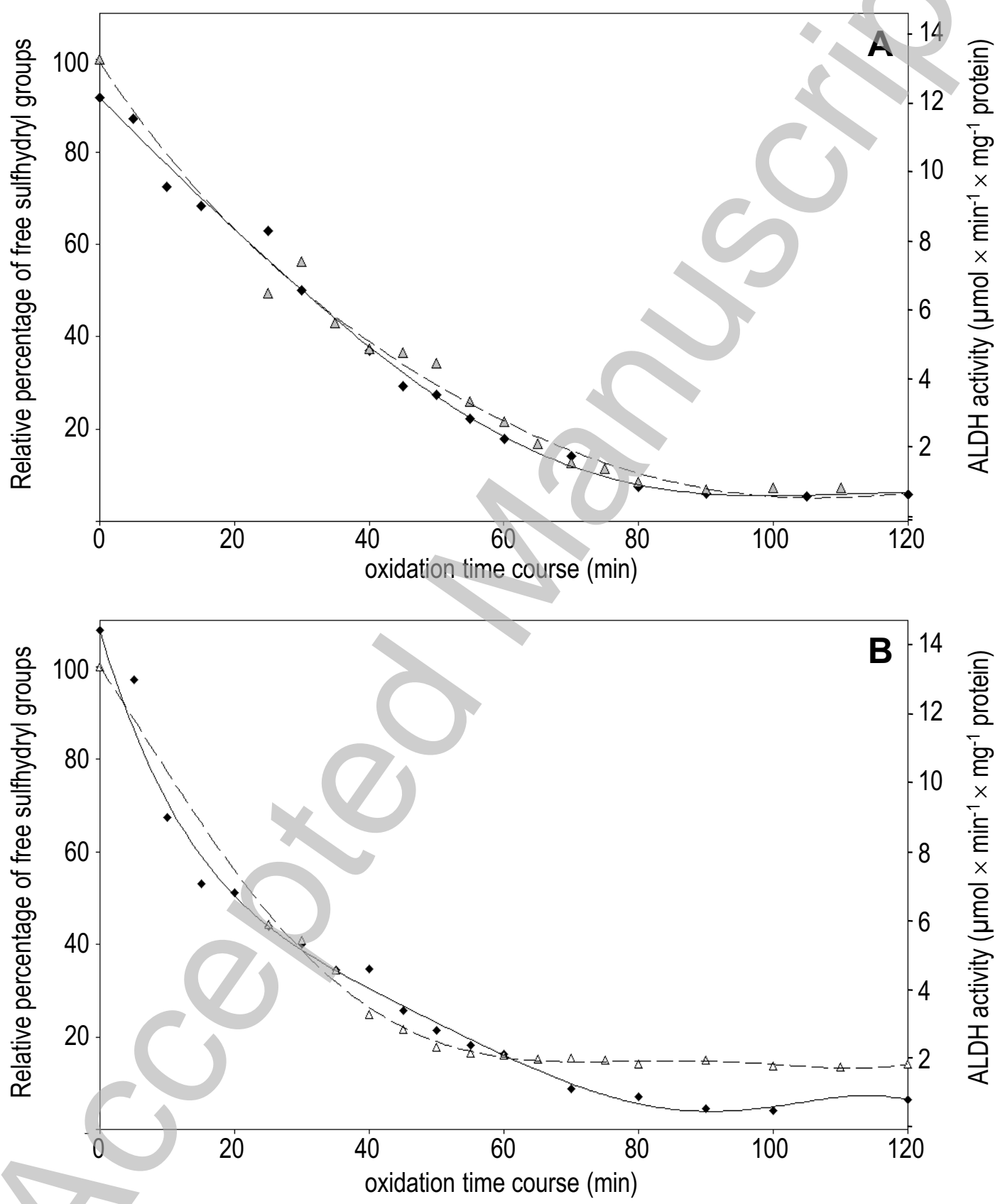

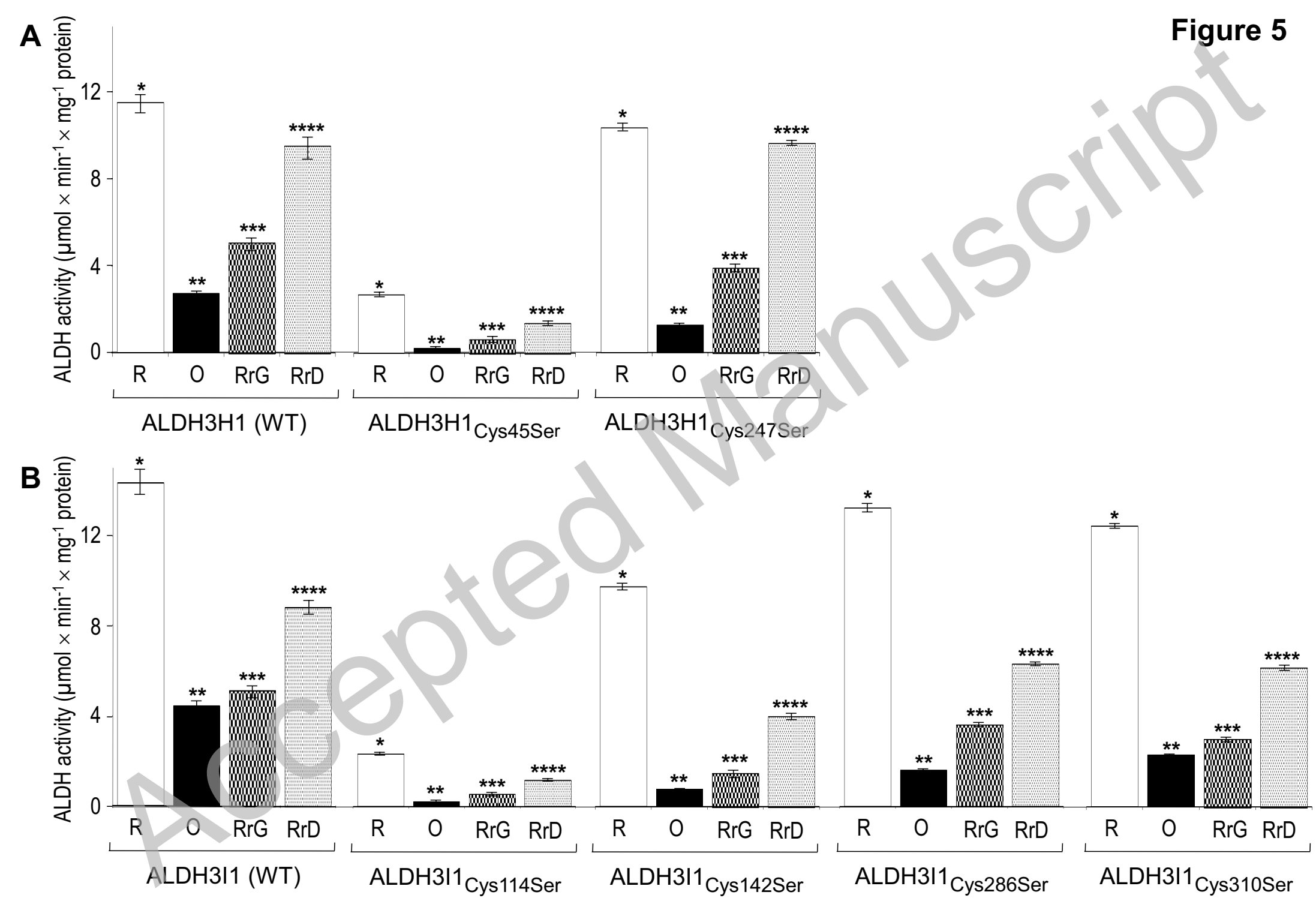

23 


\section{B Biochemical Journal Immediate Publication. Published on 20 Dec 2010 as manuscript BJ20101337}

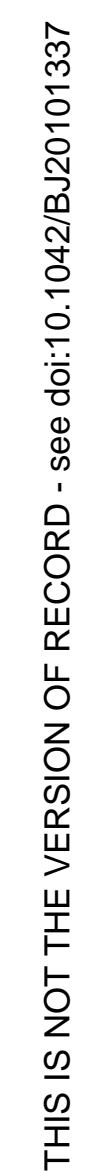

\section{Figure 6}

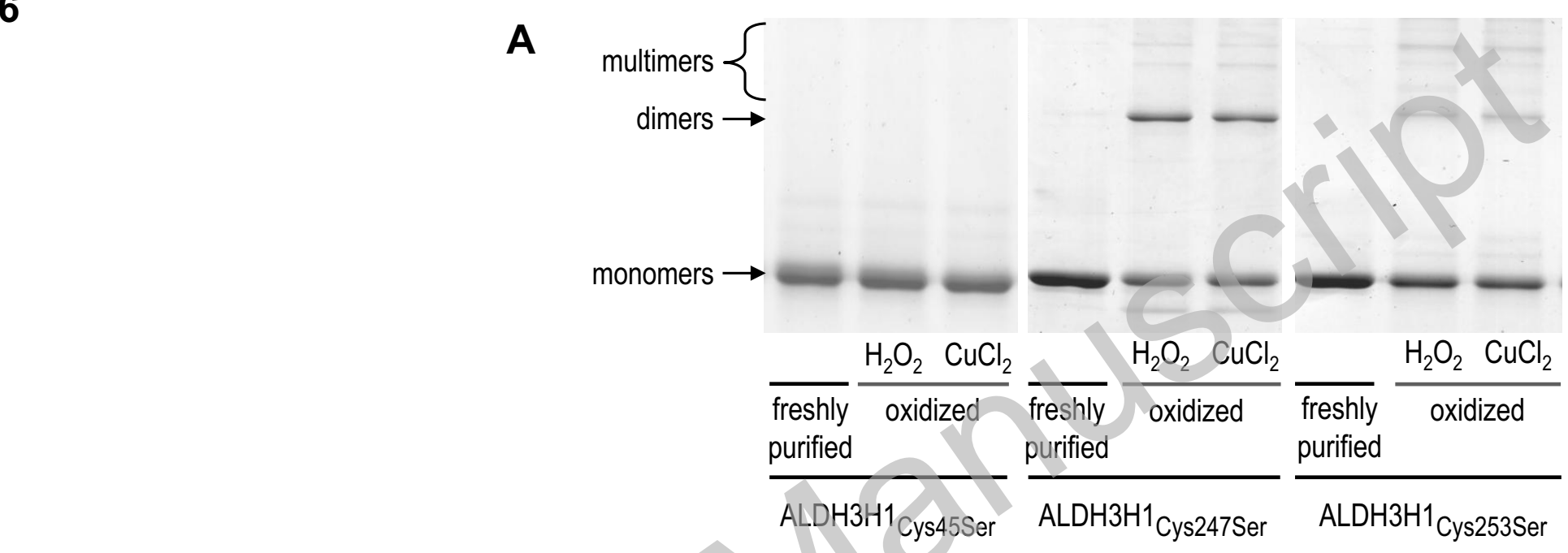

B

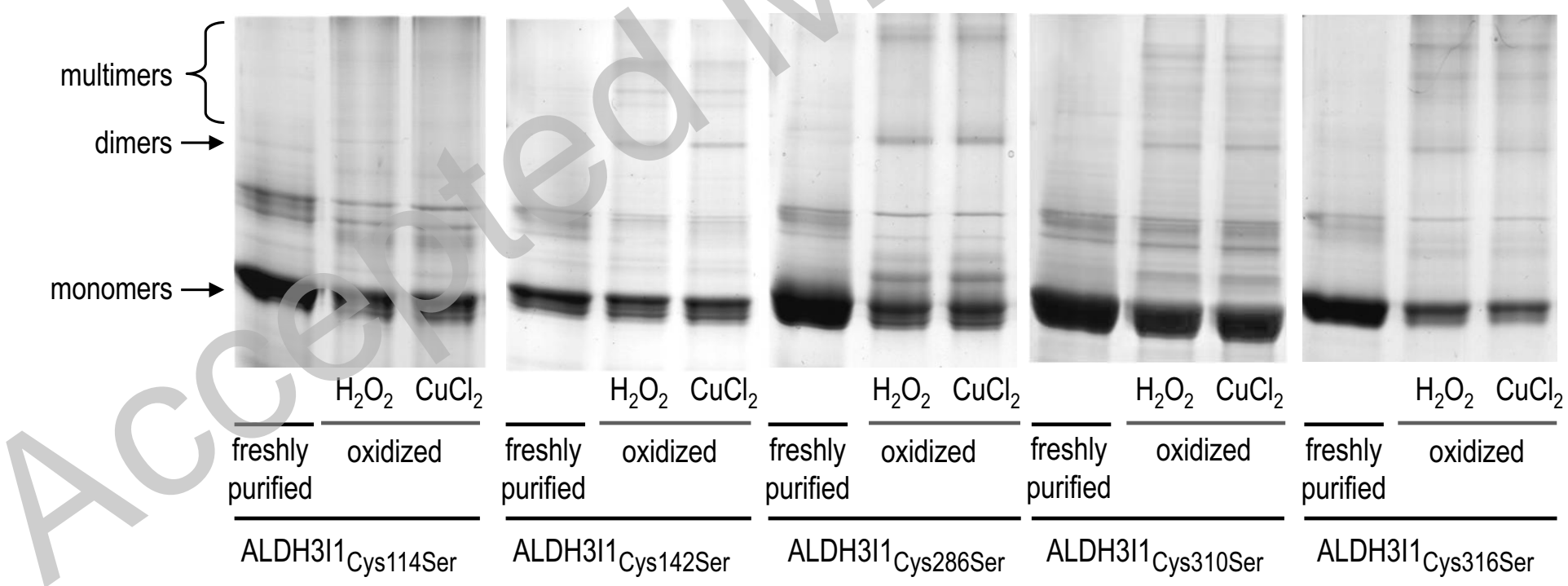

24 


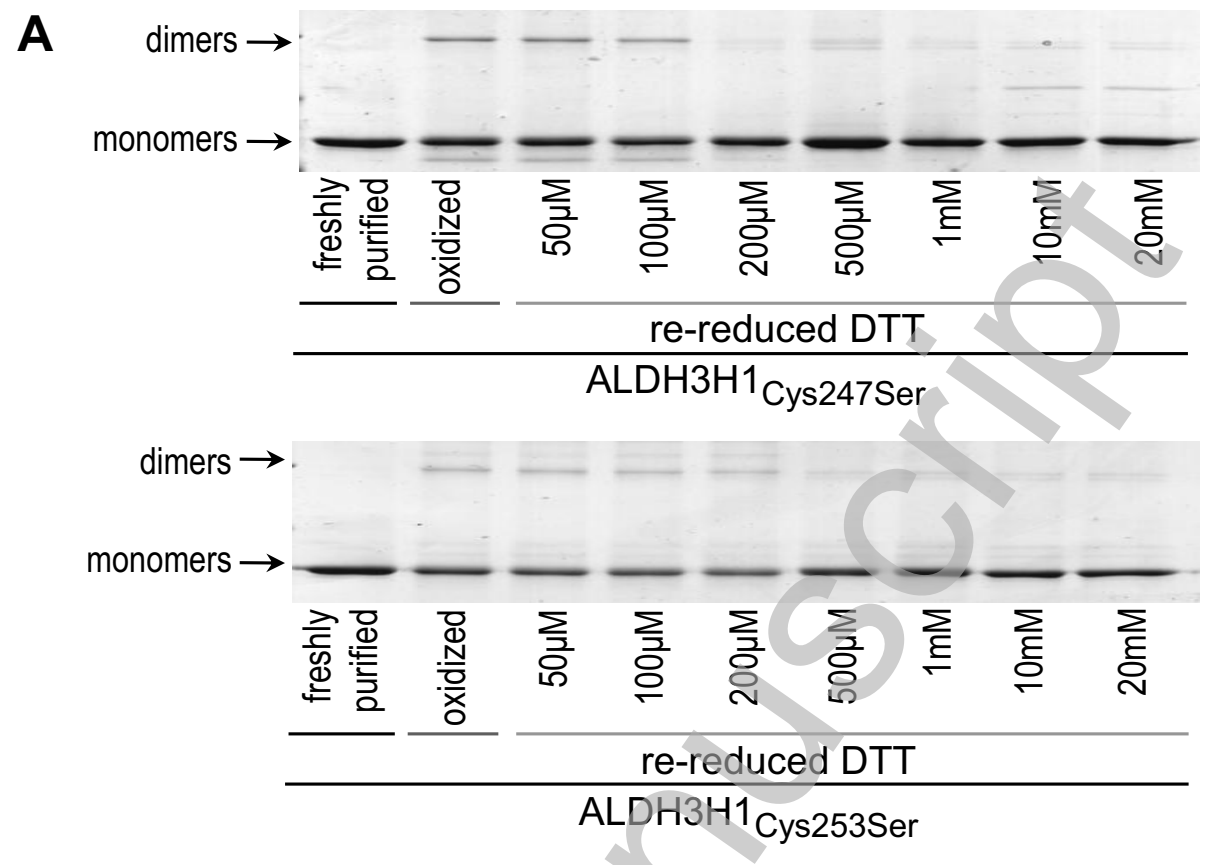

B dimers $\rightarrow$ monomers $\rightarrow$

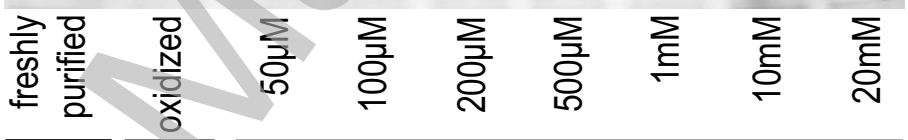
re-reduced DTT

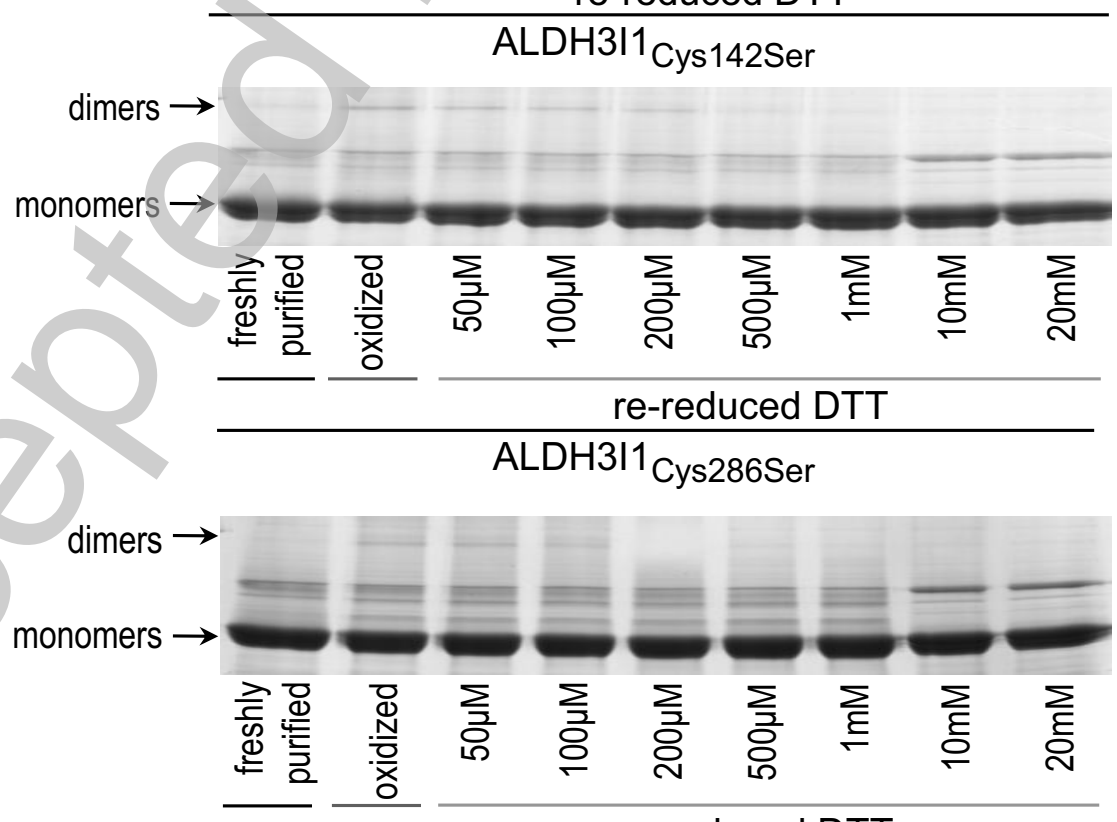

ALDH3I1 Cys310Ser 
Biochemical Journal Immediate Publication. Published on 20 Dec 2010 as manuscript BJ20101337

\section{Figure 8}

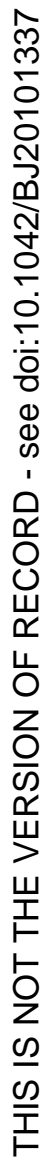

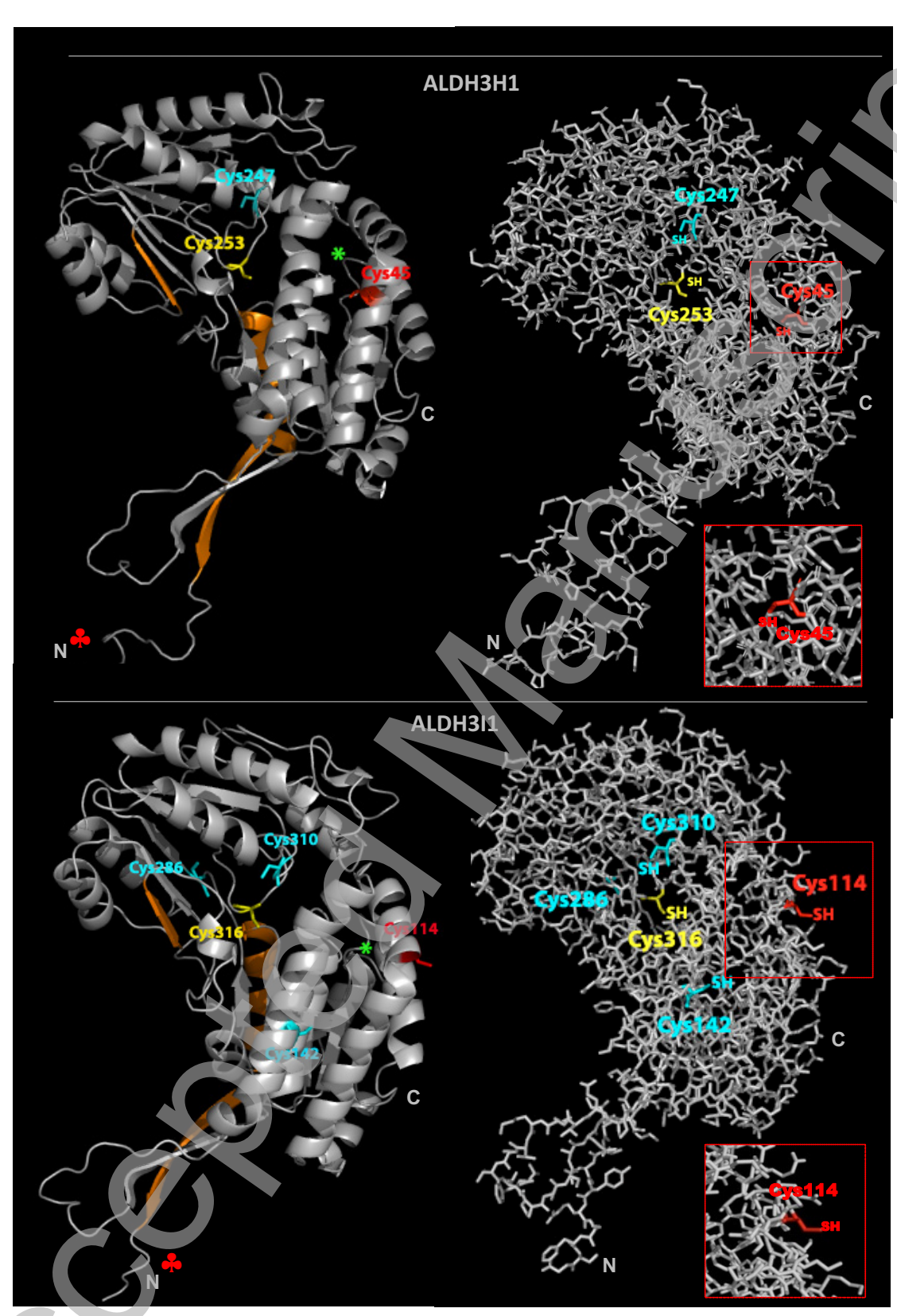

Licenced copy. Copying is not permitted, except with prior permission and as allowed by law. (C) 2010 The Authors Journal compilation (c) 2010 Portland Press Limited 